\title{
Critical impact of nitrogen vacancies in nonradical carbocatalysis on nitrogen- doped graphitic biochar
}

Zhonghao Wan ${ }^{1}$, Zibo Xu${ }^{1}$, Yuqing Sun ${ }^{1}$, Mingjing $\mathrm{He}^{1}$, Deyi Hou², Xinde Cao ${ }^{3}$, Daniel C.W. Tsang $^{1, *}$

${ }^{1}$ Department of Civil and Environmental Engineering, The Hong Kong Polytechnic University, Hung Hom, Kowloon, Hong Kong, China.

${ }^{2}$ School of Environment, Tsinghua University, Beijing 100084, China.

${ }^{3}$ School of Environmental Science and Engineering, Shanghai Jiao Tong University, 800 Dongchuan Road, Shanghai 200240, China.

* Corresponding author email: dan.tsang@polyu.edu.hk

This supporting information includes 9 Texts, 8 Tables, and 26 Figures. 


\section{Text S1. Chemicals}

Oxone $\left(2 \mathrm{KHSO}_{5} \cdot \mathrm{KHSO}_{4} \cdot \mathrm{K}_{2} \mathrm{SO}_{4}\right.$, PMS precursor), urea $\left(\mathrm{CH}_{4} \mathrm{~N}_{2} \mathrm{O}\right)$, 4-chlorophenol (4- $\mathrm{CH}$, $\mathrm{C}_{6} \mathrm{H}_{5} \mathrm{ClO}$ ), phenol ( $\mathrm{PH}, \mathrm{C}_{6} \mathrm{H}_{6} \mathrm{O}$ ), potassium bromide ( $\mathrm{KBr}$, FTIR spectrum pure), Sodium chloride ( $\mathrm{NaCl}$ ), ammonium hydroxide $\left(\mathrm{NH}_{3} \cdot \mathrm{H}_{2} \mathrm{O}, 25 w t . \%\right)$, GR, AC (granular, 20-60 mesh), humic acid (HA), and sodium azide $\left(\mathrm{NaN}_{3}\right)$ were obtained from Sigma-Aldrich Chemical Co. Ltd. 4Nitrophenol (4-NP, $\left.\mathrm{C}_{6} \mathrm{H}_{5} \mathrm{NO}_{3}\right)$, hydroquinone $\left(\mathrm{HQ}, \mathrm{C}_{6} \mathrm{H}_{6} \mathrm{O}_{2}\right)$, sodium bicarbonate $\left(\mathrm{NaHCO}_{3}\right)$, potassium carbonate $\left(\mathrm{K}_{2} \mathrm{CO}_{3}\right)$, and potassium iodide $(\mathrm{KI})$ were purchased from Aladdin Chemical Co. Ltd. Multiwalled CNTs (outer diameter $8-15 \mathrm{~nm}$, length $\sim 50 \mu \mathrm{m}$, purity $>95$ wt. $\%$ ) was purchased from Chengdu Organic Chemicals Co. Ltd. Ultrapure water (UW, $18.2 \mathrm{M} \Omega \mathrm{cm}$ ) obtained from a Millipore Milli-Q water purification system (Milford, USA) was adopted to prepare all aqueous solutions. Solvents of high-performance liquid chromatography (HPLC) grade were employed to constitute mobile phase or scavenger agents, including methanol $(\mathrm{MeOH}$, $\mathrm{CH}_{3} \mathrm{OH}$ ), ethanol (EtOH, $\left.\mathrm{C}_{2} \mathrm{H}_{5} \mathrm{OH}\right)$, tert-butyl alcohol (TBA, $\left.\mathrm{C}_{4} \mathrm{H}_{10} \mathrm{O}\right)$, and acetonitrile $\left(\mathrm{CH}_{3} \mathrm{CN}\right)$ purchased from Duksan Pure Chemicals Co. Ltd. 


\section{Text S2. Fabrication of the NCNTs}

A $1 \mathrm{~g}$ urea was completely dissolved in $500 \mathrm{~mL}$ UW prior to the addition of $1 \mathrm{~g}$ CNTs and stirred overnight. The mixture was evaporated under $80^{\circ} \mathrm{C}$ to reach a homogeneous impregnation. The slurry was transferred to a jar for the subsequent two-stage annealing in the tubular reactor under $\mathrm{N}_{2}$ purging $\left(100 \mathrm{~mL} \mathrm{~min}^{-1}\right)$, where it was dried under $120{ }^{\circ} \mathrm{C}$ for $2 \mathrm{~h}$ to remove residual moisture before being heated to $800{ }^{\circ} \mathrm{C}$ at a ramping rate of $5^{\circ} \mathrm{C} \mathrm{min}^{-1}$ and maintained for $1 \mathrm{~h}$. 


\section{Text S3. Characterization}

Scanning electron microscopy (SEM, JEOL 6490, Japan) was used to acquire the micromorphological images of the samples along with energy dispersive spectroscopy (EDS) analysis. High-resolution images were recorded on transmission electron microscopy (TEM, JEOL $2100 \mathrm{~F}$, Japan) operated at accelerating voltages of 80,120 , and $200 \mathrm{kv}$, respectively. The samples were prepared by dropping microscale solids suspended in ethanol onto a carbon-coated copper grid and dried at room temperature.

Raman spectrometer (Renishaw, UK) was employed to investigate the defective level and graphitization degree of biochar at $532 \mathrm{~nm}$ edge excitation, where all related deconvolution and area calculation were based on the OriginPro software. The X-ray photoelectron spectroscopy (XPS, Thermo Fisher Scientific, USA) with $\mathrm{Al} \mathrm{K \alpha}$ radiation was used to investigate the constitutional composition and chemical state of the elements on sample surfaces. The binding energy of all characteristic peaks were calibrated with carbon $\mathrm{C} 1 \mathrm{~s}$ core level at $284.8 \mathrm{eV}$. Devolution of XPS data was conducted using Shirley background associated with GaussianLorentzian model in XPSPEAK41, and the component peaks were identified with reference to their reported binding energies (BEs). The crystallographic structure was examined by obtaining X-ray diffraction (XRD, Bruker D8A, Germany) patterns equipped with high intensity monochromatic $\mathrm{Cu}-\mathrm{K} \alpha$ source $(\lambda=1.5218 \AA)$. Scanning rate and $2 \theta$ collection range were set at 50 $\min ^{-1}$ and $10-90^{\circ}$, respectively. MDI Jade 6.0 was employed to analyze the diffraction peaks and crystalline phases based on Joint Committee on Powder Diffraction Standards (JCPDS) database. The Fourier transform infrared (FTIR Nexus, Thermo Nicolet, USA) spectroscopy was employed to investigate the surface functionalities on biochar with the wavelength range at $400-4000 \mathrm{~cm}^{-1}$. 
The textural characteristics were determined by using $\mathrm{N}_{2}$ adsorption-desorption isotherms obtained from a surface area analyser at $77 \mathrm{~K}$ (BET, Quantachrome Autosorb, USA). The ultimate elemental analysis (EA, Vario EL cube, Germany) was used to estimate the CHONS elemental ratio in the biochar samples. The weight ratio of oxygen was quantitatively calculated using Eq.1. Zetasizer Nano ZSP instrument (Malvern, UK) was employed to measure the zeta potential of biochars under different $\mathrm{pH}$ values. Thermogravimetric analysis (TGA, Rigaku Thermo Plus) was employed to study the thermal decomposition behaviour of various carbocatalysts from $50^{\circ}$ to $1000^{\circ} \mathrm{C}$ at $5{ }^{\circ} \mathrm{C} \mathrm{min}^{-1}$ heating rate with Ar stripping gas. The metal concentrations after wet digestion ( $\left(0.1 \mathrm{~g}\right.$ sample in $4 \mathrm{~mL} \mathrm{HNO}_{3}$ and $1 \mathrm{~mL} \mathrm{HClO}_{4}$ under $105^{\circ} \mathrm{C}$ heating till total evaporation) were measured using an atomic absorption spectroscopy (AAS, Jena, LOD of $0.1 \mu \mathrm{g} \mathrm{L}^{-1}$ ).

$\mathrm{O} w t . \%=100 \%-\mathrm{C} w t . \%-\mathrm{H} w t . \%-\mathrm{N} w t . \%-\mathrm{S} w t . \%-\mathrm{ash} w t . \%$ 


\section{Text S4. Detailed Procedure for EPR Test}

The electron paramagnetic resonance (EPR) spectra were obtained using an EMX10/12 spectrometer (EMX10/12, Bruker, Germany). The applied instrumental conditions were as follows: resonance frequency of $9.82 \mathrm{GHz}$, microwave power of $20.07 \mathrm{~mW}$, modulation frequency of $100 \mathrm{kHz}$, modulation amplitude of $1.0 \mathrm{G}$, sweep width of $100 \mathrm{G}$, time constant of $40.96 \mathrm{~ms}$, sweep time of $83.93 \mathrm{~s}$, and receiver gain of $2.0 \times 10^{4}$ at room temperature. In the sample vials, 150 mM 5,5-dimethyl-1-pyrroline-N-oxide (DMPO) or 2, 2, 6, 6-tetramethyl-4-piperidinol (TEMP) was added as the spin-trapping agent in a buffer solution $(\mathrm{pH}=7.4,20 \mathrm{mM}$ phosphate). Peak intensities of the DMPO- $\mathrm{SO}_{4}, \mathrm{DMPO}-\mathrm{OH}$, and TEMPN signals at 5 min were applied as indexes of the generated ROS after the correction of background noise.

All EPR scanning was repeated in triplicate and the sum value was output for $G$ factor calculation. The raw data of the EPR signal (arbitrary units) was processed through the cwEsr software (3.3.36E XB version) provided by JEOL for directly reading the G factors, which were calculated based on the equation $\mathrm{h} \cdot \mathrm{f}=\mathrm{g} \cdot \mathrm{m}_{\mathrm{B}} \cdot \mathrm{B}$, where $\mathrm{h}, \mathrm{f}, \mathrm{m}_{\mathrm{B}}$, and B signify Planck's constant equal to $6.62 \times 10^{34} \mathrm{~J} \cdot \mathrm{s}$, applied microwave frequency, Bohr Magneton $\left(9.27 \times 10^{-27} \mathrm{~J} / \mathrm{mT}\right)$, and magnetic field strength, respectively. Specifically, the constant mass (15 $\mathrm{mg})$ of $\mathrm{BC}$ was added into a micro pipette, following placed in the detector for recording signal. The parameters of EPR experiments were set as follows: center field $3460 \mathrm{G}$, sweep width $100 \mathrm{G}$, microwave frequency 9.71 GHz, microwave power $19.71 \mathrm{~mW}$, modulation frequency $100 \mathrm{kHz}$, modulation amplitude of $1.0 \mathrm{G}$, and sweep time of $83.97 \mathrm{~s}$. 


\section{Text S5. Activity Evaluation}

The catalytic activity of all the biochar samples was assessed in batch experiments using the Oxone as oxidant for contaminant degradation in aqueous solution. The $\mathrm{pH}$ value of experimental solution was measured using a digital $\mathrm{pH}$ meter (Thermo, USA) and adjusted with $0.1 \mathrm{M} \mathrm{NaOH}$ and $\mathrm{HNO}_{3}$ to maintain a circumneutral environment at $6.0 \pm 0.2$. No buffer agent was involved to avoid any misleading results, as conventional buffer (carbonate, bicarbonate, or phosphorus) may scavenge the radicals or influence the surface properties of carbon. Specifically, $100 \mathrm{~mL}$ solution containing a specific amount of pollutant (e.g., $100 \mathrm{mg} \mathrm{L}^{-1}$ ) was put in a $250 \mathrm{~mL}$ conical flask covered with foil. Subsequently, $200 \mathrm{mg} \mathrm{L}^{-1}$ biochar and $1 \mathrm{~g} \mathrm{~L}^{-1}$ Oxone powder (equivalent to 3.25 mM PMS) were sequentially added to initiate the reaction. All experiments were conducted at 25 $\pm 1{ }^{\circ} \mathrm{C}$ (if not otherwise specified) with vigorous stirring at $200 \mathrm{rpm}$ in an oscillator without light irradiation. An aliquot of $1 \mathrm{~mL}$ solution was periodically withdrawn from solutions at predetermined time interval, and then promptly transferred into HPLC vials after passing through a $0.45 \mu \mathrm{m}$ mixed cellulose ester membrane filter (MCE, Millipore). A $0.5 \mathrm{~mL} \mathrm{MeOH}$ was immediately mixed with the extracted solution to terminate the catalytic reaction. The degradation results obtained in the first 30 min were adopted for the kinetic analysis. All batch experiments were performed in duplicate (or triplicate if needed), and the mean values with corresponding standard deviations were reported in this study. 


\section{Text S6. Analytical Methods}

The concentrations of different pollutants were analysed using a HPLC (limit of detection (LOD) of $0.1 \mathrm{mg} \mathrm{L}^{-1}$, Hitachi) equipped with a C-18 column (Eclipse XDB-C18) and an Ultraviolet and visible spectrophotometry (UV-VIS) Detector with UV wavelength set at specific values. The mobile phase was a mixture of absolute methanol and phosphorus acid $(0.5$ vol. $\%)$ with different volume ratios at a certain flow rate. The concentrations of $\mathrm{PH}, 4-\mathrm{CH}, 4-\mathrm{NP}$, and HQ were analysed by HPLC (limit of detection (LOD) of $0.1 \mathrm{mg} \mathrm{L}^{-1}$, Hitachi) equipped with a C-18 column (Eclipse XDB-C18) and an Ultraviolet and visible spectrophotometry (UV-VIS) Detector with UV wavelength set at 260-280 $\mathrm{nm}$. The released $\mathrm{Cl}^{-}$and $\mathrm{SO}_{4}{ }^{2-}$ ions were detected using an ion chromatography system (Thermo Scientific). Total carbon (TC) consisting of total organic carbon (TOC) and inorganic carbon (IC) was measured using a TOC analyser (Multi 3100, LOD of $1 \mu \mathrm{g}$ $\left.\mathrm{L}^{-1}\right)$ 


\section{Text S7. Procedures for PMS Adsorption and In-situ Raman Analysis}

The residual persulfate concentration was determined by a photometrical method using potassium iodide. Specifically, a chromogenic reagent containing $100 \mathrm{~g} \mathrm{~L}^{-1} \mathrm{KI}$ and $0.5 \mathrm{~g} \mathrm{~L}^{-1}$ $\mathrm{NaHCO}_{3}$ was prepared. The reagent was allowed to equilibrate for $15 \mathrm{~min}$, and then $10 \mathrm{~mL}$ reagent was transferred into a $15 \mathrm{~mL}$ polypropylene centrifuge tube. An aliquot of $0.25 \mathrm{~mL}$ sample from the reaction system was introduced, and the mixture was thoroughly mixed for a few seconds and allowed to stand for $20 \mathrm{~min}$. The absorbance of the yellow solution was measured using an Optizen Pop UV-Vis spectrometer (LOD of $1 \mathrm{mg} \mathrm{L}^{-1}$, PerkinElmer) at a wavelength of $352 \mathrm{~nm}$.

The in-situ Raman experiment was conducted using a shortened quartz cuvette $(20 \times 12.5 \times 3.5$ $\mathrm{mm}$ ) as container. The $532 \mathrm{~nm}$ green laser was vertically focalized at the cuvette bottom prior to the test. With the addition of $10 \mathrm{mg}$ biochar and a certain amount of solution containing dissolved 3.25 mM PMS in the cuvette, a tube shaker was applied to ensure the homogeneous suspension of solids. After vigorously mixing for $30 \mathrm{~s}$, the Raman laser was launched with a scanning range from 700 to $1400 \mathrm{~cm}^{-1}$. The Raman depth scanning within $0.8 \mathrm{~nm}$ was also carried out to explore the surface properties change before and after nitrogen doping. 


\section{Text S8. Durability, Recyclability, and Regeneration}

The naturally aging process was conducted as follows. $10 \mathrm{~g}$ specific biochar was stored in a 500 L Teflon beaker covered with an apertured PTFE lid. The diameter of those pores on lid was manually perforated and maintained between $0.5-2 \mathrm{~mm}$, which merely allowed the entrance of rain drops but undesirable impurities. The beaker was transferred to an outdoor rooftop for a 30-day aging in the summer of Hong Kong (2020.07.12-2020.08.11), where the specified biochar could undergo high temperature, rain washing, and atmospheric oxidation. After the aging process, the treated biochar was washed using UW for several times, oven-dried $\left(60^{\circ} \mathrm{C}\right)$, and stored in an airtight container prior to its future use.

After each run, all separated biochar samples were put in $100 \mathrm{~mL}(1 / 100 \mathrm{w} / \mathrm{v} \%) \mathrm{UW}$ and underwent sonication for $20 \mathrm{~min}$ to remove the absorbed intermediates. After drying under vacuum environment, these samples were reused for another run to test the recyclability without the involvement of thermal treatment.

Regarding the regeneration of biochar, an annealing process was carried out to remediate the surface oxidation and remove the poisoning chemicals bound on biochar surface. Specifically, the $3^{\text {rd }}$ used biochar samples were placed in a tubular furnace under nitrogen purging $\left(100 \mathrm{~mL} \mathrm{~min}^{-1}\right)$, heated to $800{ }^{\circ} \mathrm{C}$ with a ramping rate of $5^{\circ} \mathrm{C} \mathrm{min}^{-1}$ and maintained for $1 \mathrm{~h}$. The regenerated biochar was collected and applied for catalytic reaction without further treatment. 


\section{Text S9. Procedures to Measure COD and BOD.}

COD was measured via a chemical titration method using ferrous ammonium sulfate as the titrant. Specifically, $20 \mathrm{~mL}$ of aqueous sample was put into a $500 \mathrm{~mL}$ flask and $20 \mathrm{~mL}$ UW was also prepared in parallel as the blank. Then, a suitable amount of solid $\mathrm{HgSO}_{4}$ together with $5 \mathrm{~mL}$ conc. $\mathrm{H}_{2} \mathrm{SO}_{4}$ was added to remove $\mathrm{Cl}^{-}$interference. $10 \mathrm{~mL}$ standard $\mathrm{K}_{2} \mathrm{Cr}_{2} \mathrm{O}_{7}$ was promptly added under continuous shaking. After the careful addition of $25 \mathrm{~mL} \mathrm{H}_{2} \mathrm{SO}_{4}$ containing dissolved $\mathrm{Ag}_{2} \mathrm{SO}_{4}$, the mixed solution in flask was attached to a condenser with a cooling system and proceeded the heating program for $2 \mathrm{~h}$. The cooled-down liquid was titrated with standardized ferrous ammonium sulfate using Ferrion solution as the indicator. The end point of titration could be reached when the color of solution changed from blue-green to reddish brown.

$\mathrm{COD}=\frac{(\mathrm{A}-\mathrm{B}) \times \mathrm{N} \times 8000}{\text { sample volume }}\left(\mathrm{mg} \mathrm{L}^{-1}\right)$

where $\mathrm{A}, \mathrm{B}$, and $\mathrm{N}$ correspond to the volumes of ferrous ammonium sulfate used in titration for blank and sample as well as the normality of applied ferrous ammonium sulfate solution, respectively.

BOD was determined via monitoring the dissolved oxygen (DO) change after constant temperature incubation. Specifically, $20 \mathrm{~mL}$ of aqueous sample (or properly diluted solution) was transferred into a BOD bottle. Determine the DO values $\left(\mathrm{DO}_{\mathrm{t}=0}\right)$ of the samples and $\mathrm{UW}$ blanks using DO meter before their incubation under $20^{\circ} \mathrm{C}$ for 5 days. After incubation, the final DO values $\left(\mathrm{DO}_{\mathrm{t}=5}\right)$ were also measured for the calculation of BOD.

$\mathrm{BOD}=\frac{\mathrm{D}_{1}-\mathrm{D}_{2}(1-\mathrm{P})}{\mathrm{P}}\left(\mathrm{mg} \mathrm{L}^{-1}\right)$

where $D_{1}$ and $D_{2}$ signify the DO differences between the final and initial value for samples and blanks, respectively, while P indicates the decimal volumetric fraction of sample in BOD bottle. 
Table S1. Physicochemical properties of the NBCs.

\begin{tabular}{|c|c|c|c|c|c|c|}
\hline & $\mathrm{DBC}$ & BMDBC & NBC500 & NBC600 & NBC700 & NBC800 \\
\hline BET surface area, $\mathrm{S}_{\mathrm{BET}}\left(\mathrm{m}^{2} \mathrm{~g}^{-1}\right)$ & 366 & 246 & 395 & 391 & 374 & 353 \\
\hline Micropore area, $S_{\text {micro }}\left(\mathrm{m}^{2} \mathrm{~g}^{-1}\right)$ & 259 & 175 & 288 & 266 & 266 & 167 \\
\hline External surface area, $S_{\text {ext }}\left(\mathrm{m}^{2} \mathrm{~g}^{-1}\right)$ & 106 & 70 & 106 & 125 & 107 & 186 \\
\hline Total pore volume, $\mathrm{V}_{\text {total }}\left(\mathrm{cm}^{3} \mathrm{~g}^{-1}\right)$ & 0.27 & 0.17 & 0.28 & 0.29 & 0.28 & 0.31 \\
\hline Micropore volume, $V_{\text {micro }}\left(\mathrm{cm}^{3} \mathrm{~g}^{-1}\right)$ & 0.14 & 0.09 & 0.15 & 0.15 & 0.14 & 0.09 \\
\hline $\mathrm{V}_{\text {micro }} / \mathrm{V}_{\text {total }}(\%)$ & 51.85 & 52.94 & 53.57 & 51.72 & 50.00 & 29.03 \\
\hline Average pore diameter, $D_{p}(n m)$ & 2.91 & 2.86 & 2.91 & 2.96 & 3.01 & 3.59 \\
\hline Approximate $\mathrm{O} / \mathrm{C}$ ratio $^{a}$ & 7.21 & 8.78 & 12.58 & 9.07 & 8.05 & 3.52 \\
\hline Ultimate $\mathrm{O} / \mathrm{C}$ ratio $^{\mathrm{b}}$ & 9.77 & 7.48 & 15.91 & 3.00 & 5.80 & 7.66 \\
\hline Ultimate $\mathrm{N}$ content & 0.34 & 0.80 & 0.62 & 0.48 & 0.44 & 0.23 \\
\hline
\end{tabular}

${ }^{a}$ Calculated from SEM-Mapping scanning (at.\%).

${ }^{\mathrm{b}}$ Obtained from elemental analysis (wt.\%). 
Table S2. Elemental composition of the NBCs based on XPS survey.

\begin{tabular}{llll}
\hline & \multicolumn{2}{l}{ Atomic percentage (at. $\%)$} & N 1s \\
\cline { 2 - 4 } & C 1s & O 1s & ND $^{\text {a }}$ \\
\hline DBC & 92.45 & 7.45 & 5.08 \\
BMDBC & 80.34 & 14.54 & 3.41 \\
NBC500 & 80.48 & 15.08 & 3.24 \\
NBC600 & 80.66 & 15.17 & 3.51 \\
NBC700 & 80.86 & 15.14 & ND \\
\hline
\end{tabular}

${ }^{a}$ Not detected. 
Table S3. Disorder and graphitization analysis of the NBCs based on Raman deconvolution.

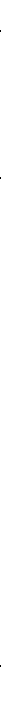


Table S4. Selected phenols for substrate specificity test.

\begin{tabular}{|c|c|c|c|}
\hline & Formula & $\mathrm{pK}_{\mathrm{a}}$ & Structure \\
\hline 4-Chlorophenol & $\mathrm{C}_{6} \mathrm{H}_{5} \mathrm{ClO}$ & 9.4 & \\
\hline Phenol & $\mathrm{C}_{6} \mathrm{H}_{6} \mathrm{O}$ & 9.9 & \\
\hline Hydroquinone & $\mathrm{C}_{6} \mathrm{H}_{6} \mathrm{O}_{2}$ & 9.9 & \\
\hline 4-Nitrophenol & $\mathrm{C}_{6} \mathrm{H}_{5} \mathrm{NO}_{3}$ & 7.15 & \\
\hline
\end{tabular}


Table S5. G factors of the biochars.

\begin{tabular}{ll}
\hline & G-factor \\
\hline DBC & ND \\
NBC500 & 2.0038 \\
NBC600 & 2.0031 \\
NBC700 & 2.0025 \\
NBC800 & 2.0021 \\
Spent NBC800 & 2.0042 \\
Aged NBC800 & 2.0026 \\
\hline
\end{tabular}


Table S6. Detailed information of the scavengers.

\begin{tabular}{|c|c|c|}
\hline & Reagents & Target electroactive components \\
\hline \multirow{6}{*}{$\begin{array}{l}\text { Radicals } \\
\text { scavengers }\end{array}$} & Ethanol & $\begin{array}{l}\mathrm{k}\left(\cdot \mathrm{SO}_{4}^{-}\right)=(1.6-7.7) \times 10^{9} \mathrm{M}^{-1} \mathrm{~s}^{-1}, \\
\mathrm{k}(\cdot \mathrm{OH})=(1.2-1.8) \times 10^{9} \mathrm{M}^{-1} \mathrm{~s}^{-1}\end{array}$ \\
\hline & Tert-butanol & $\begin{array}{l}\mathrm{k}\left(\cdot \mathrm{SO}_{4}^{-}\right)=(4.0-9.5) \times 10^{5} \mathrm{M}^{-1} \mathrm{~s}^{-1}, \\
\mathrm{k}(\cdot \mathrm{OH})=(3.2-7.6) \times 10^{8} \mathrm{M}^{-1} \mathrm{~s}^{-1}\end{array}$ \\
\hline & $\mathrm{NaN}_{3}$ & $\mathrm{k}\left({ }^{1} \mathrm{O}_{2}\right)=1.0 \times 10^{9} \mathrm{M}^{-1} \mathrm{~s}^{-1}$ \\
\hline & $\mathrm{Cl}^{-}$ & $\begin{array}{l}\mathrm{k}\left(\cdot \mathrm{SO}_{4}^{-}\right)=4.3 \times 10^{9} \mathrm{M}^{-1} \mathrm{~s}^{-1}, \\
\mathrm{k}(\cdot \mathrm{OH})=3.1 \times 10^{8} \mathrm{M}^{-1} \mathrm{~s}^{-1}\end{array}$ \\
\hline & $\mathrm{CO}_{3}^{2-}$ & $\begin{array}{l}\mathrm{k}\left(\cdot \mathrm{SO}_{4}^{-}\right)=6.1 \times 10^{6} \mathrm{M}^{-1} \mathrm{~s}^{-1}, \\
\mathrm{k}(\cdot \mathrm{OH})=3.9 \times 10^{8} \mathrm{M}^{-1} \mathrm{~s}^{-1}\end{array}$ \\
\hline & $\mathrm{HCO}_{3}^{-}$ & $\begin{array}{l}\mathrm{k}\left(\cdot \mathrm{SO}_{4}^{-}\right)=1.6 \times 10^{6} \mathrm{M}^{-1} \mathrm{~s}^{-1} \\
\mathrm{k}(\cdot \mathrm{OH})=8.5 \times 10^{6} \mathrm{M}^{-1} \mathrm{~s}^{-1}\end{array}$ \\
\hline
\end{tabular}


Table S7. Detailed information for the simulated phenolic wastewaters.

\begin{tabular}{|c|c|c|c|c|c|c|c|c|c|c|c|c|c|}
\hline \multirow{3}{*}{ Type ${ }^{a}$} & \multirow{3}{*}{$\mathrm{pH}$} & \multicolumn{2}{|c|}{$\mathrm{TC}^{\mathrm{b}}$} & \multirow{2}{*}{$\begin{array}{l}\text { Initial } \\
\text { COD }\end{array}$} & \multirow{2}{*}{$\begin{array}{l}\text { Initial } \\
\text { BOD }\end{array}$} & \multirow{2}{*}{$4-\mathrm{CH}$} & \multirow{2}{*}{$\mathrm{PH}$} & \multirow{3}{*}{ HQ } & \multirow{3}{*}{ 4-NP } & \multirow{3}{*}{$\mathrm{TP}^{\mathrm{c}}$} & \multirow{3}{*}{$\begin{array}{l}\text { Catalyst } \\
\text { Dosage } \\
\left(\mathrm{mg} \mathrm{L}^{-1}\right) \\
\end{array}$} & \multirow{3}{*}{$\begin{array}{c}\text { Oxidant } \\
\begin{array}{c}\text { Dosage } \\
(\mathrm{mM})\end{array} \\
\end{array}$} & \multirow{3}{*}{$\begin{array}{l}\text { NP/oxidant } \\
\text { ratio }^{d}\end{array}$} \\
\hline & & TOC & $\mathrm{IC}$ & & & & & & & & & & \\
\hline & & \multicolumn{6}{|c|}{ Concentration $\left(\mathrm{mg} \mathrm{L}^{-1}\right)$} & & & & & & \\
\hline I -1 & 7.45 & 60.79 & 17.69 & 176.4 & 0.42 & 100 & - & - & - & 100 & 500 & 3.25 & \\
\hline I -2 & 7.58 & 78.13 & 18.25 & 229.8 & 1.32 & - & 100 & - & - & 100 & 500 & 3.25 & \\
\hline I -3 & 6.08 & 66.62 & 17.52 & 150.2 & 3.12 & - & - & 100 & - & 100 & 500 & 3.25 & \\
\hline I -4 & 6.35 & 55.51 & 16.34 & 190.4 & 0.27 & - & - & - & 100 & 100 & 500 & 3.25 & $1: 10$ \\
\hline II -1 & $\begin{array}{l}5.94 \\
6.08\end{array}$ & $\begin{array}{l}187.8 \\
178.0\end{array}$ & $\begin{array}{l}18.09 \\
16.45\end{array}$ & $\begin{array}{l}547.4 \\
566.3\end{array}$ & $\begin{array}{l}0.27 \\
0.87\end{array}$ & 100 & 100 & 100 & - & 300 & 500 & 9.75 & \\
\hline II -2 & 5.92 & 238.4 & 17.00 & 745.2 & 0.42 & 100 & 100 & - & 100 & 300 & 500 & 9.75 & \\
\hline III & 7.30 & 8.595 & 17.87 & 8.2 & 0.57 & 100 & 100 & 100 & 100 & 400 & 500 & 13.00 & - \\
\hline Background & & & & & & - & - & - & - & - & - & - & \\
\hline
\end{tabular}

${ }^{\mathrm{a}} \mathrm{HA}\left(50 \mathrm{mg} \mathrm{L}^{-1}\right)$ was selected as the representative $\mathrm{NOM} . \mathrm{NaCl}, \mathrm{K}_{2} \mathrm{CO}_{3}$, and $\mathrm{NaHCO}_{3}\left(20 \mathrm{mg} \mathrm{L}^{-1}\right.$ for each) were selected as the natural ionic constituents.

b Total carbon (TC) incorporates total organic carbon (TOC) and inorganic carbon (IC).

c Total concentration of phenols.

d $3.25 \mathrm{mM}$ PMS is equivalent to $1000 \mathrm{mg} \mathrm{L}^{-1}$ Oxone dosage. 
Table S8. The parameters after catalytic reaction.

\begin{tabular}{llllll}
\hline Type & Final pH & Final TOC & \multicolumn{2}{c}{ Final COD } & Final BOD \\
\cline { 3 - 5 } & & \multicolumn{3}{c}{ Concentration $\left(\mathrm{mg} \mathrm{L}^{-1}\right)$} \\
I -1 & 2.81 & 31.12 & 61.55 & 15.42 & 0.2505 \\
I -2 & 2.77 & 40.51 & 68.12 & 16.32 & 0.2395 \\
I -3 & 2.66 & 35.46 & 36.11 & 19.62 & 0.5433 \\
I -4 & 2.71 & 34.06 & 110.8 & 15.72 & 0.1418 \\
II -1 & 2.61 & 141.7 & 343.0 & 17.37 & 0.0506 \\
II -2 & 2.68 & 131.7 & 338.1 & 17.97 & 0.0531 \\
III & 2.61 & 181.9 & 572.0 & 15.72 & 0.0274 \\
Background + BC & 9.27 & 4.923 & 8.2 & 0.12 & - \\
Background + Oxone & 2.90 & 4.626 & 8.2 & 0.12 & - \\
\hline
\end{tabular}




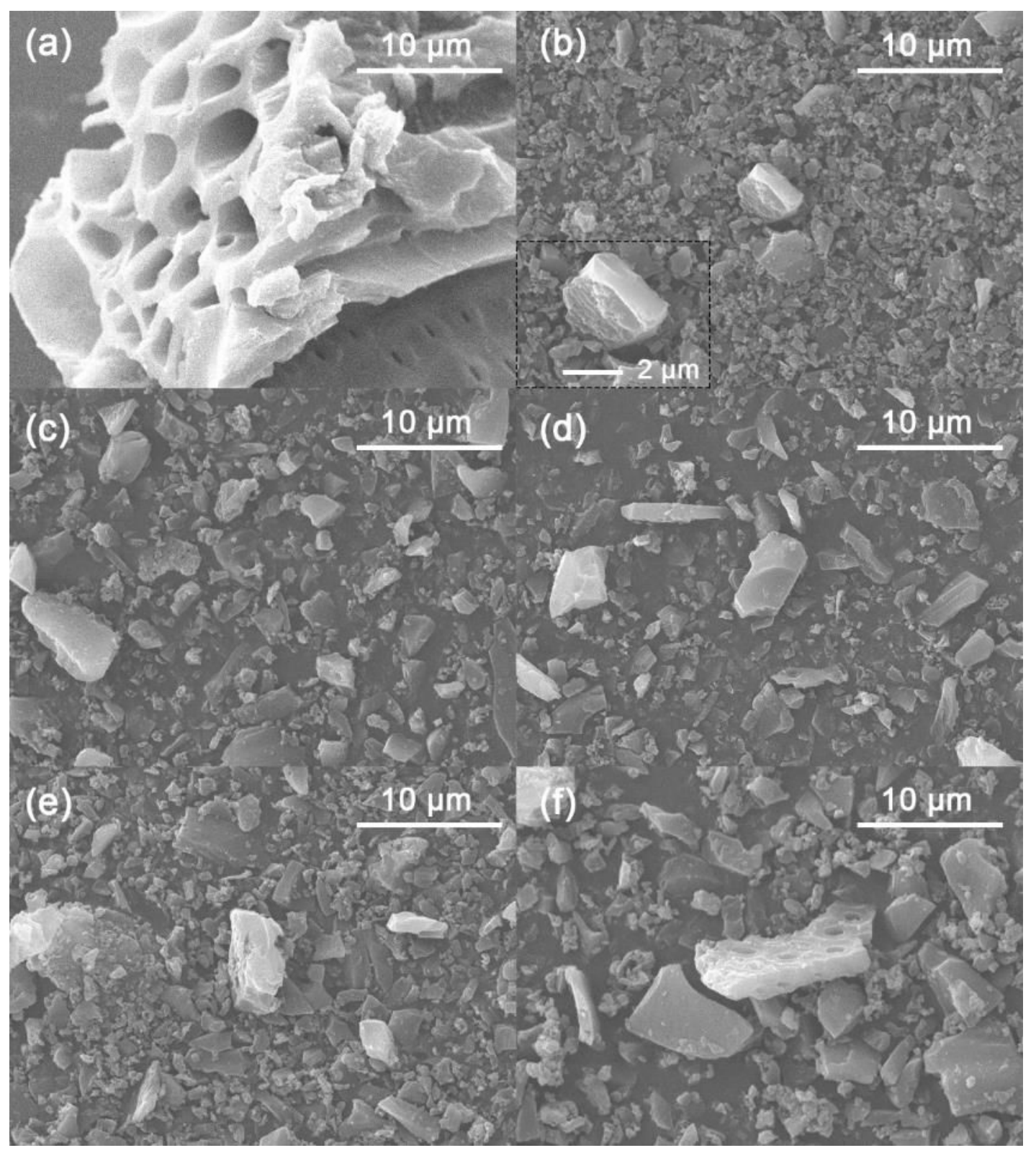

Figure S1. SEM images of the (a) DBC, (b) BMDBC, (c) NBC500, (d) NBC600, (e) NBC700, and (f) NBC800 at a magnification of $8 \mathrm{k}$. 


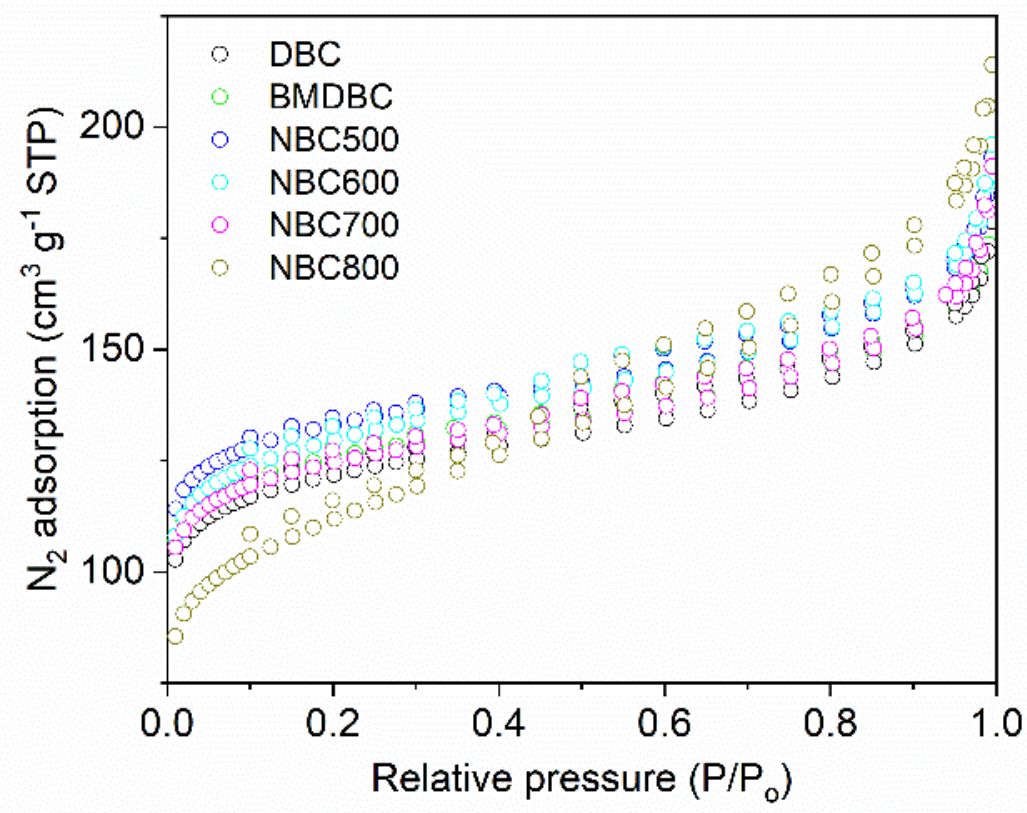

Figure S2. Nitrogen adsorption-desorption isotherms of the biochars. 


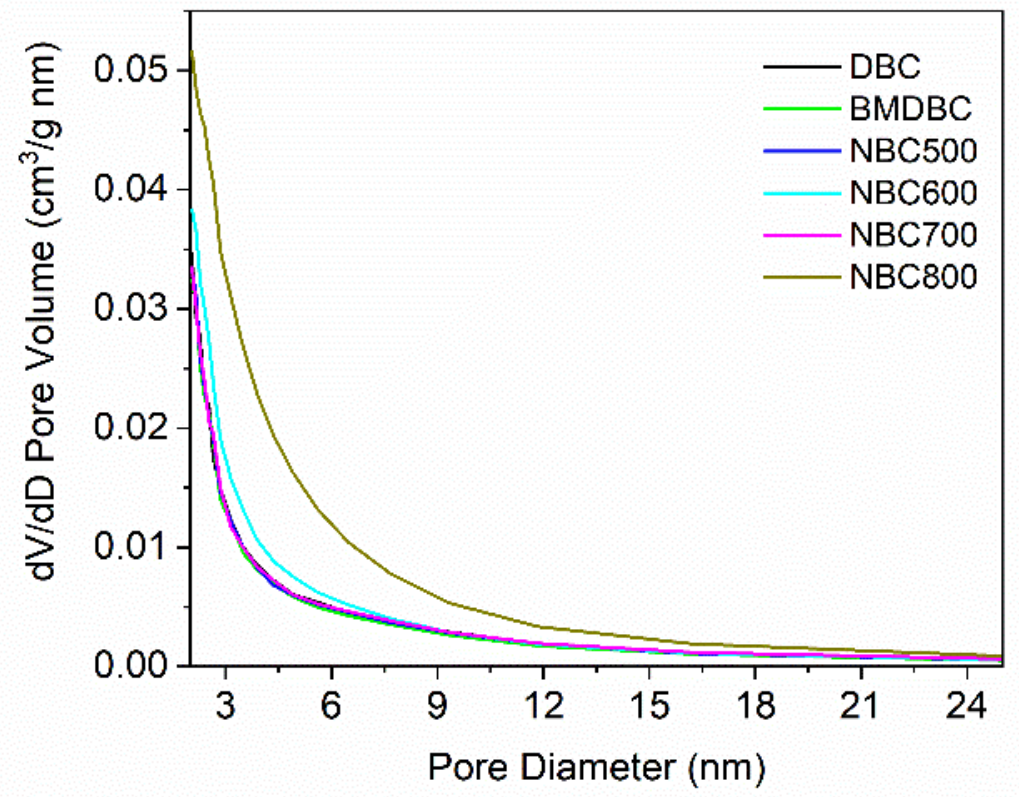

Figure S3. Pore size distribution of the biochars. 


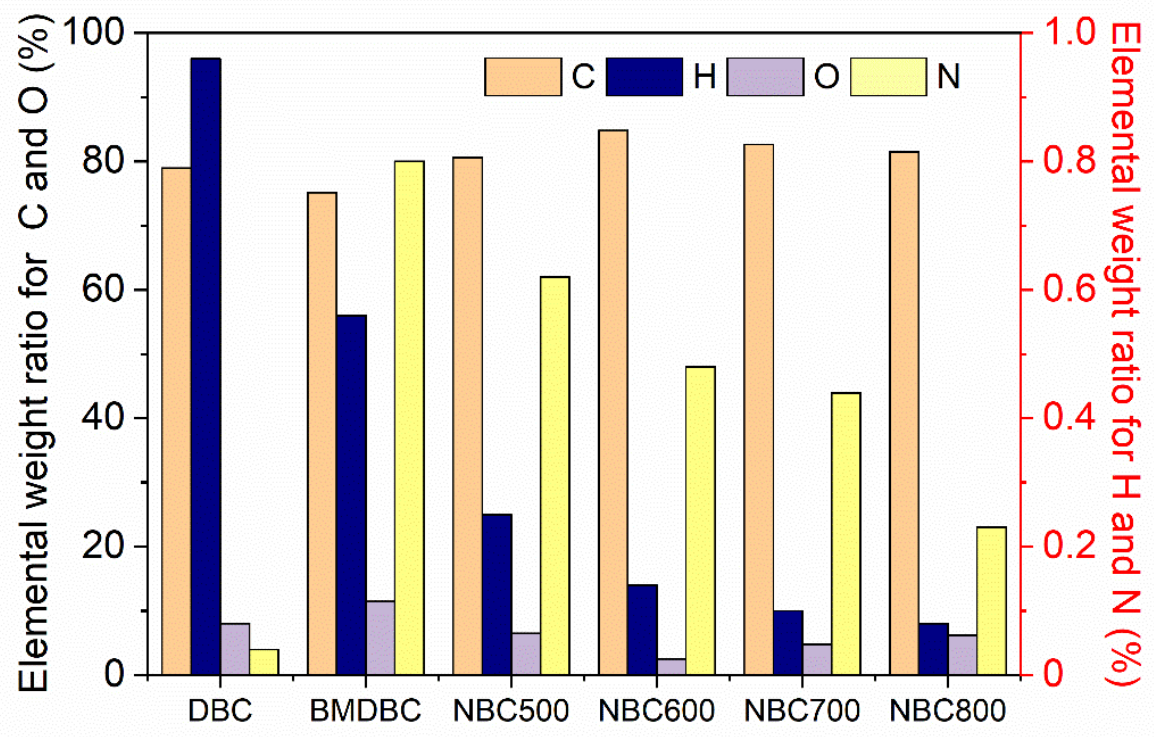

Figure S4. Elemental analysis of the DBCs and NBCs. 


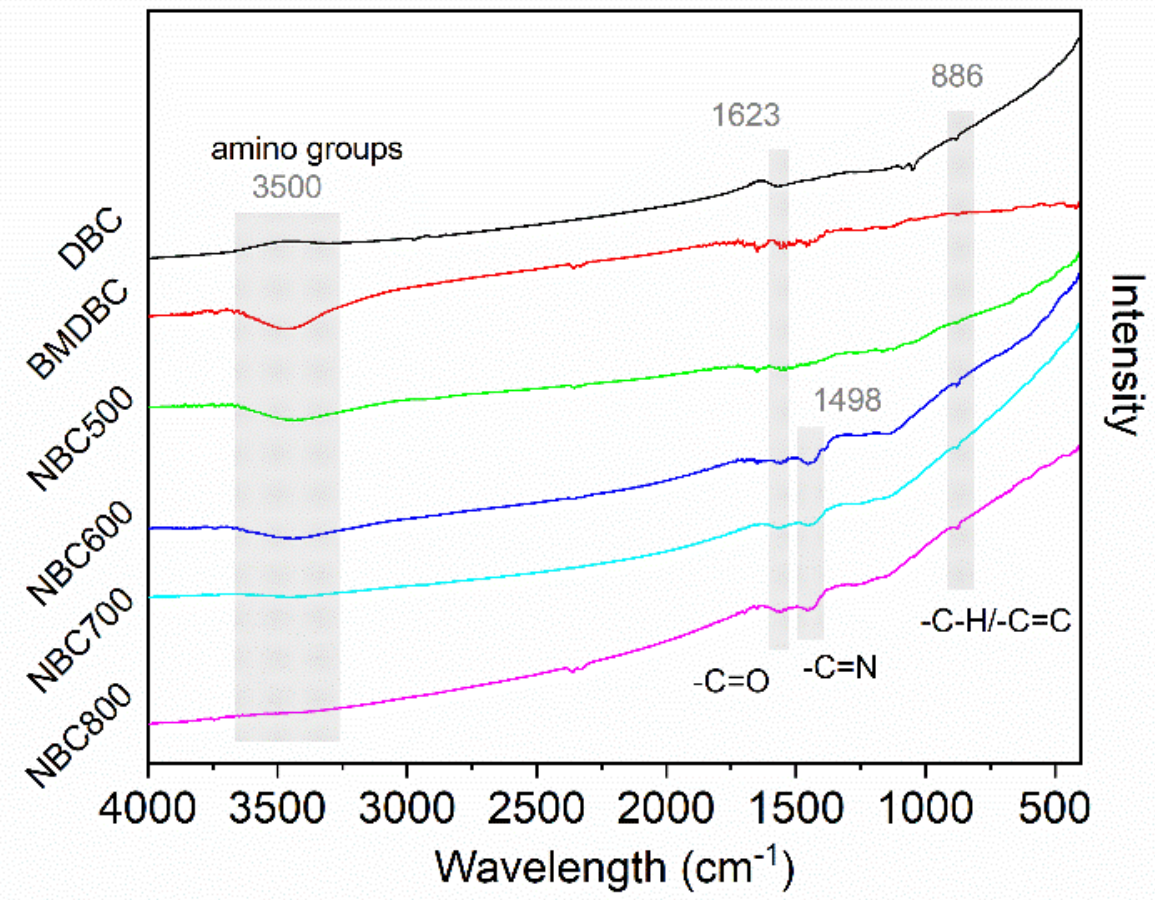

Figure S5. FTIR curves of the DBCs and NBCs. 


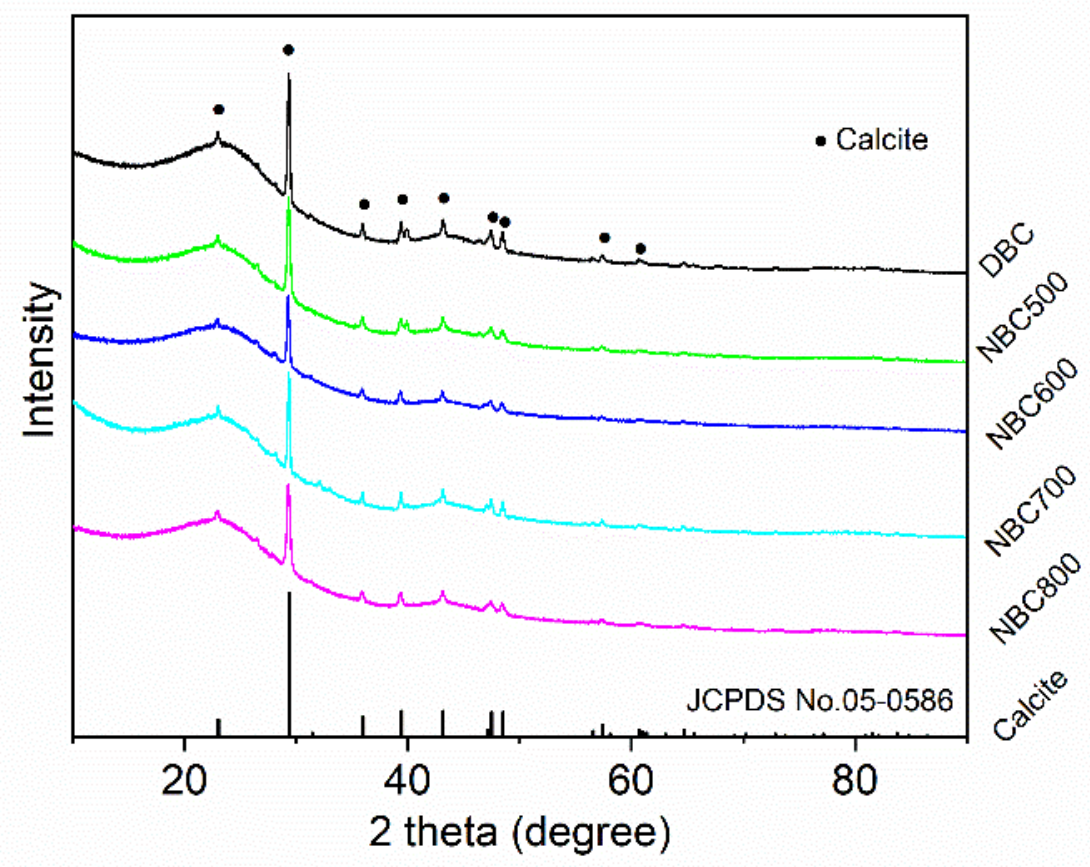

Figure S6. XRD patterns of the DBC and NBCs. 

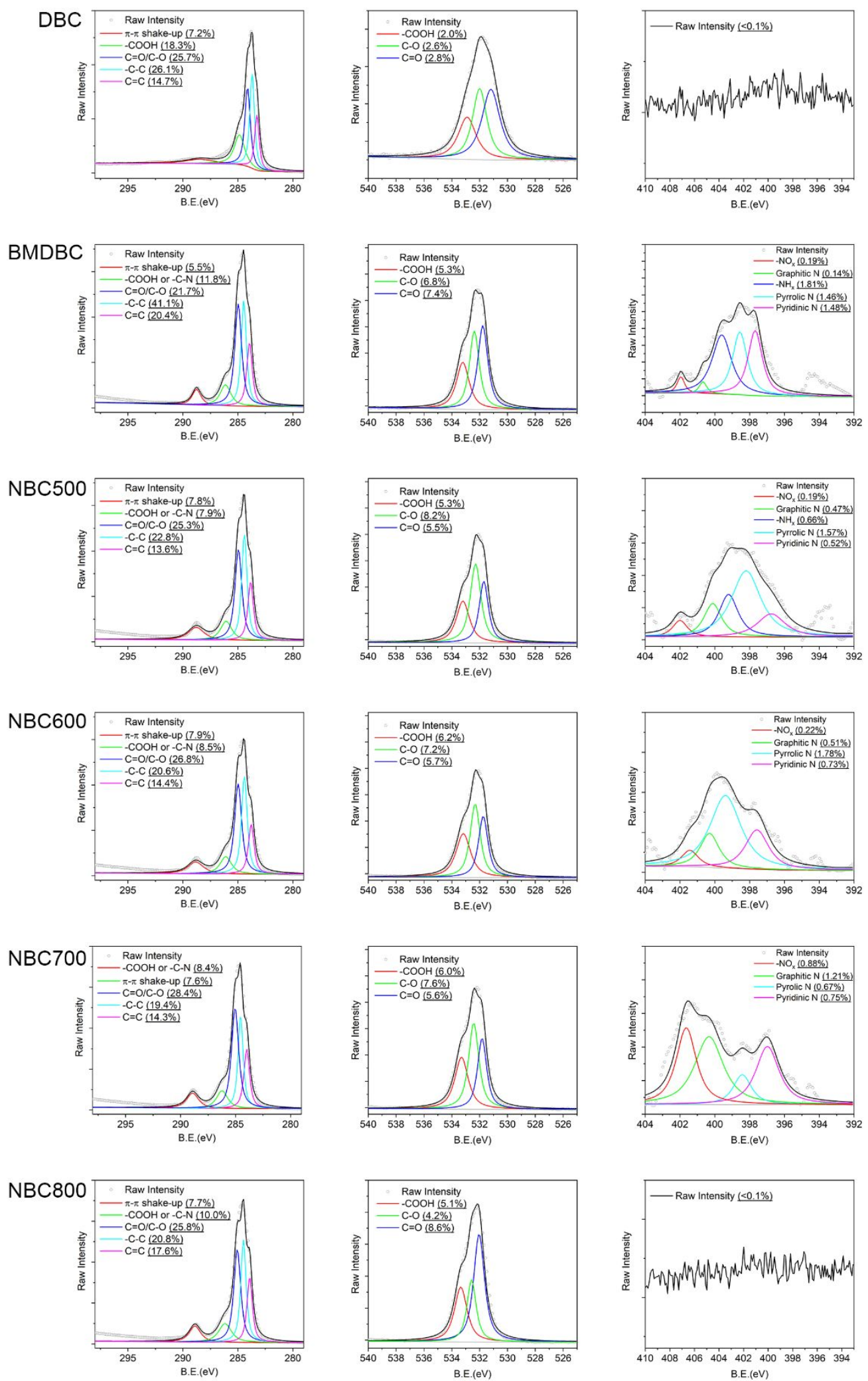

Figure S7. XPS deconvolution for all biochars. 

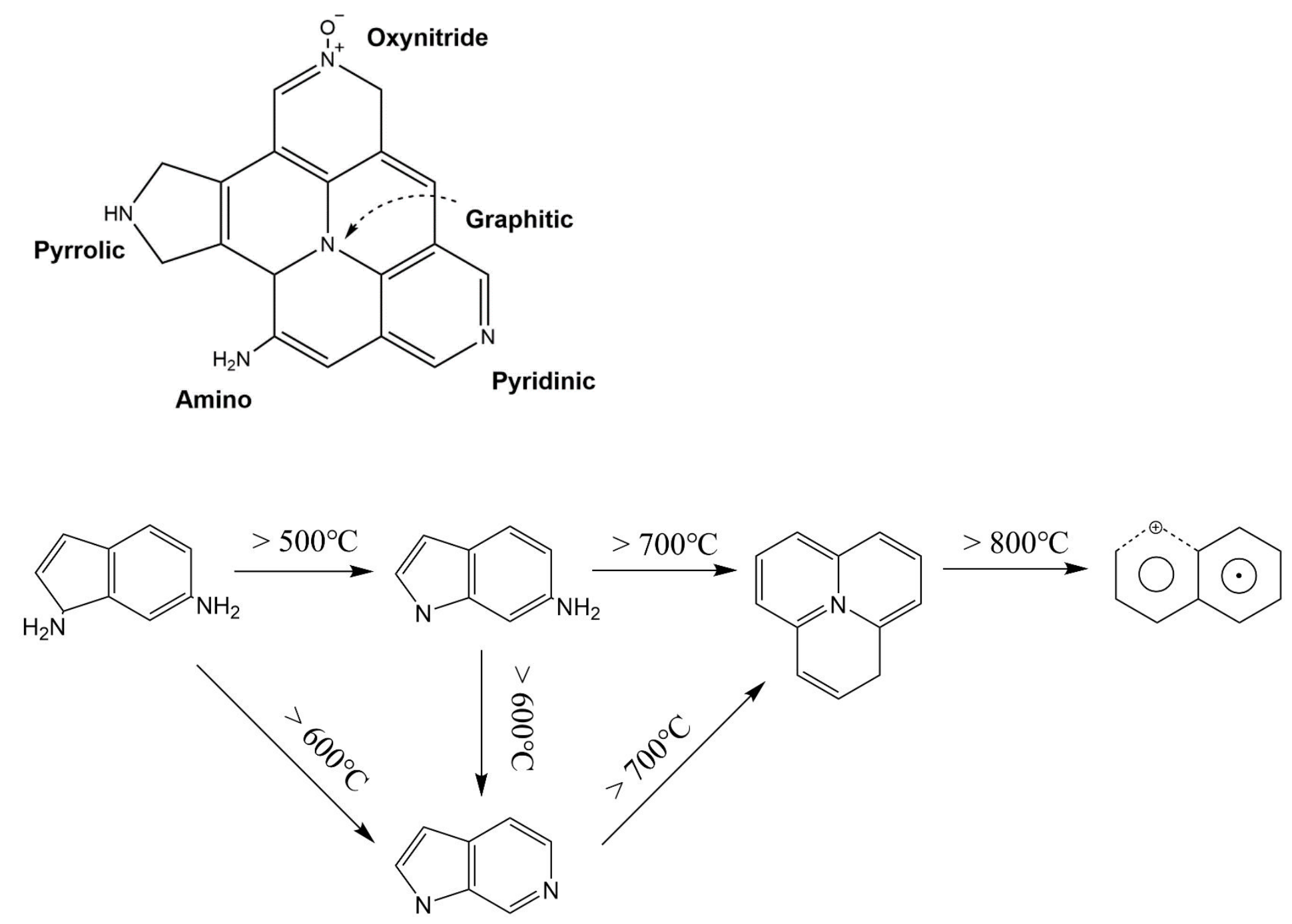

Figure S8. Main nitrogen dopants on the carbons and the nitrogen species transformation on the NBCs. 


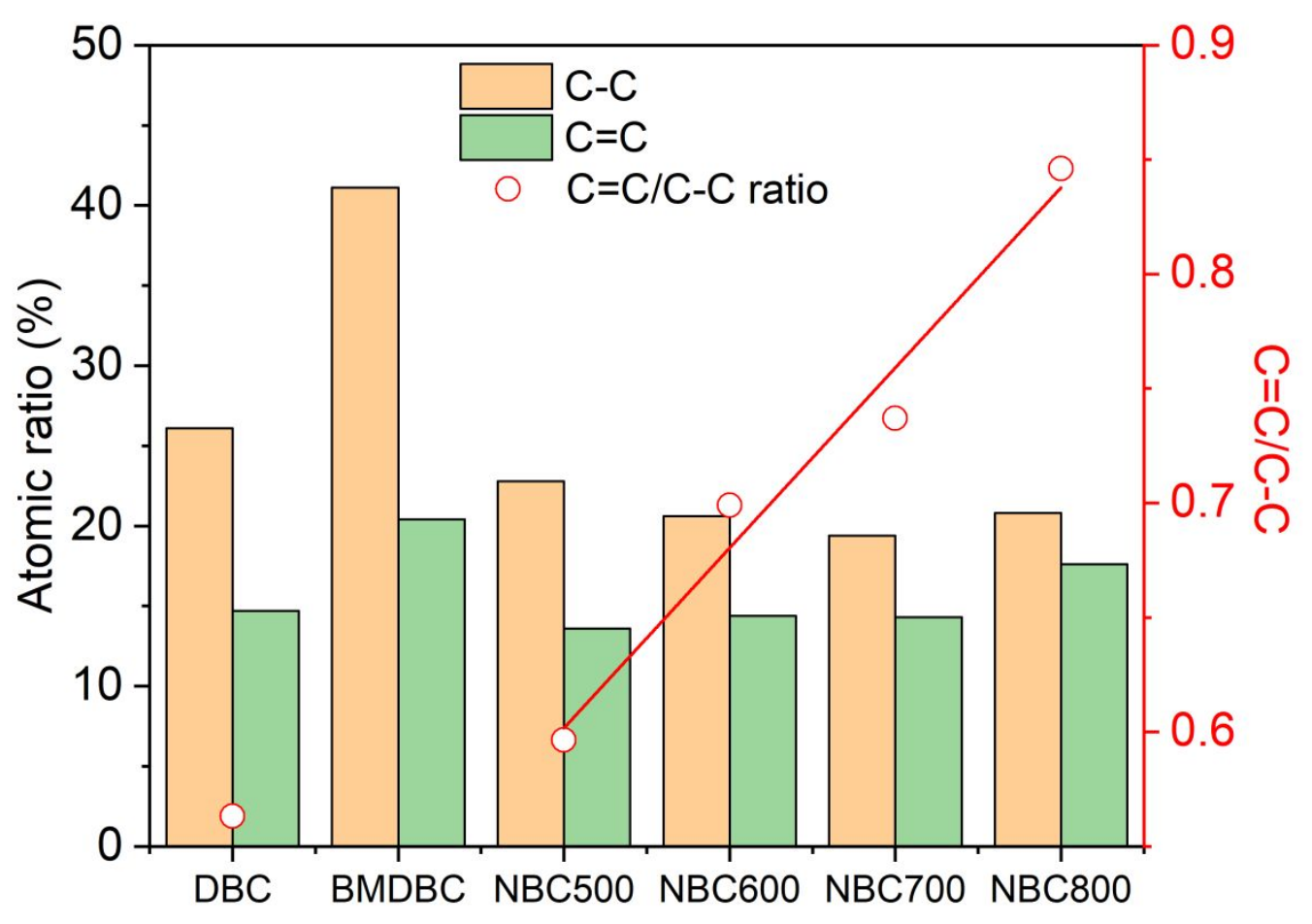

Figure S9. Graphitization indicators for the DBCs and NBCs. 


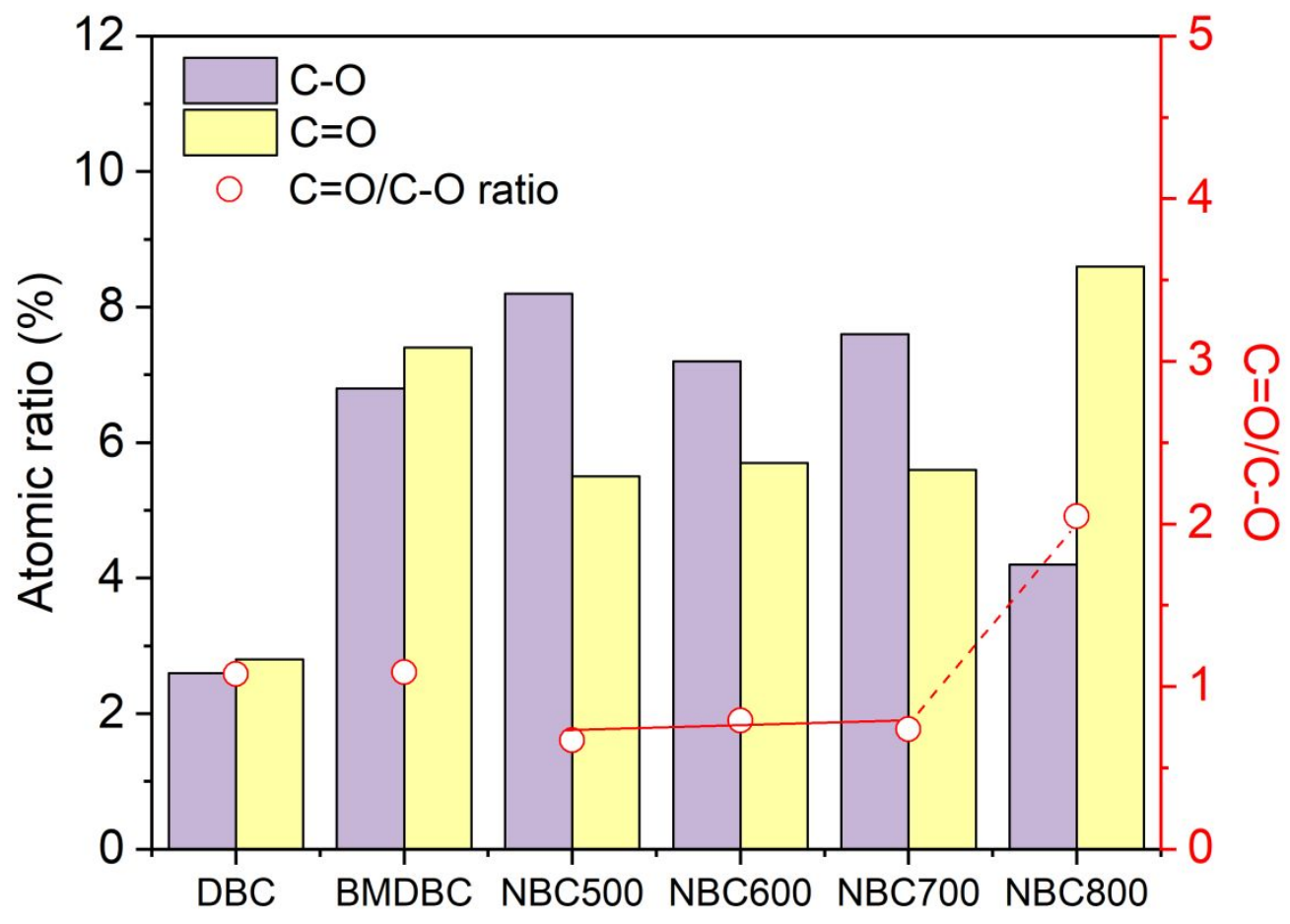

Figure S10. Oxygen functional group densities of the DBCs and NBCs. 

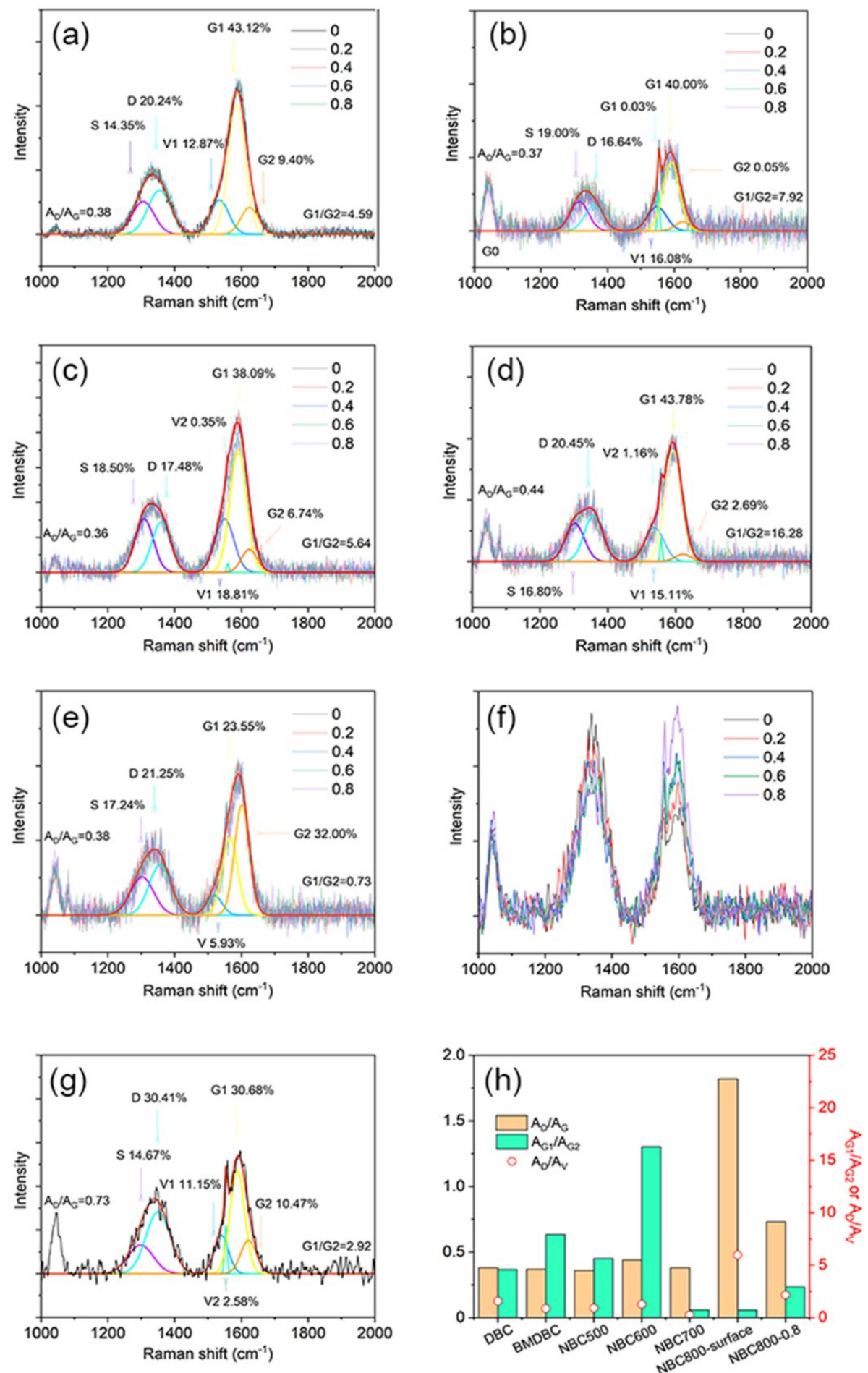

Figure S11. Deconvoluted results for Raman depth analysis of the (a) DBC, (b) BMDBC, (c) NBC500, (d) NBC600, (e) NBC 700, (f) original NBC800, (g) NBC800-0.8, and (h) summary of indicators. 


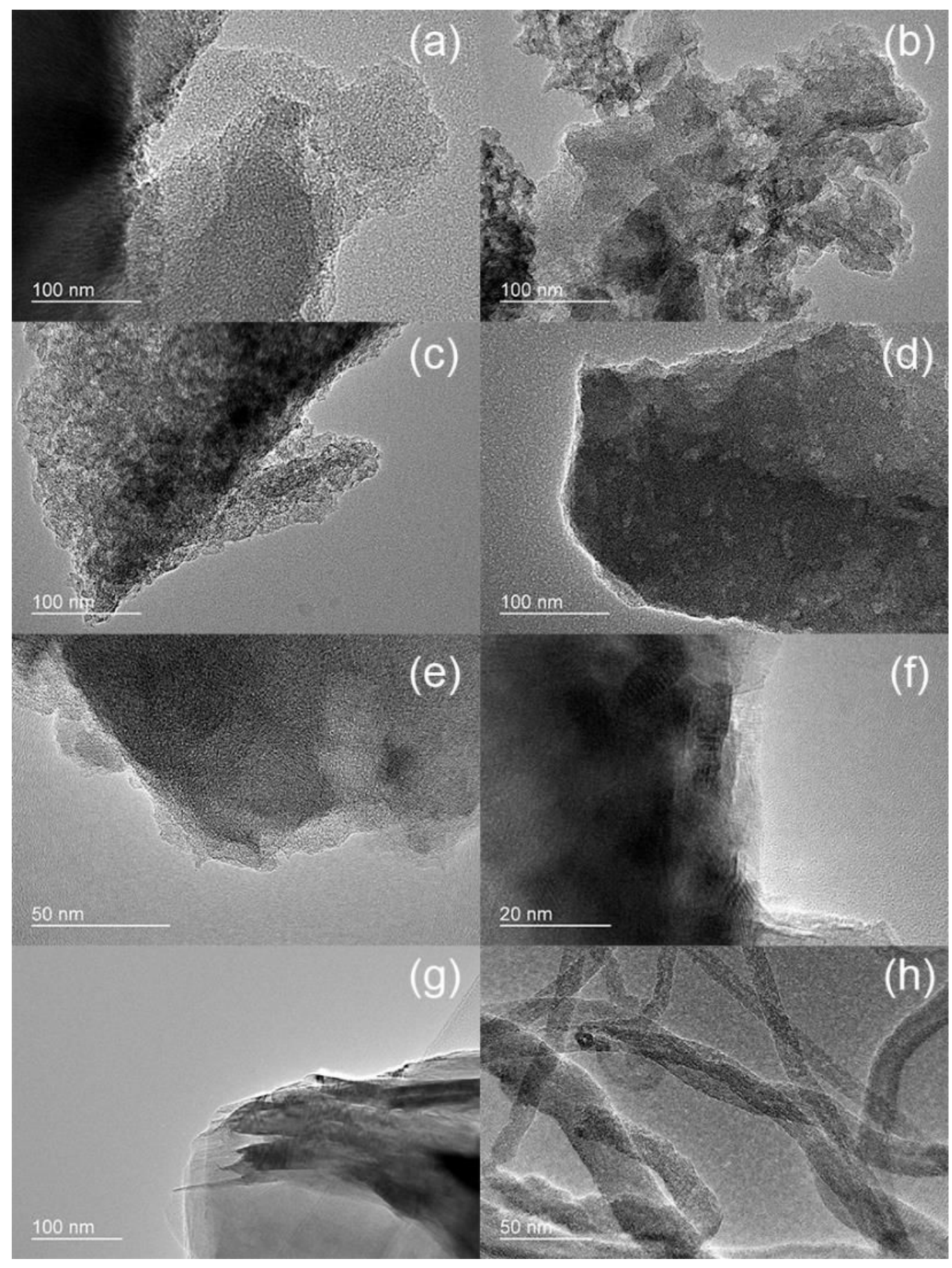

Figure S12. High-resolution images for the (a) DBC, (b) BMDBC, (c) NBC500, (d) NBC600, (e) NBC700, (f) NAC, (g) NG, and (h) NCNTs. 


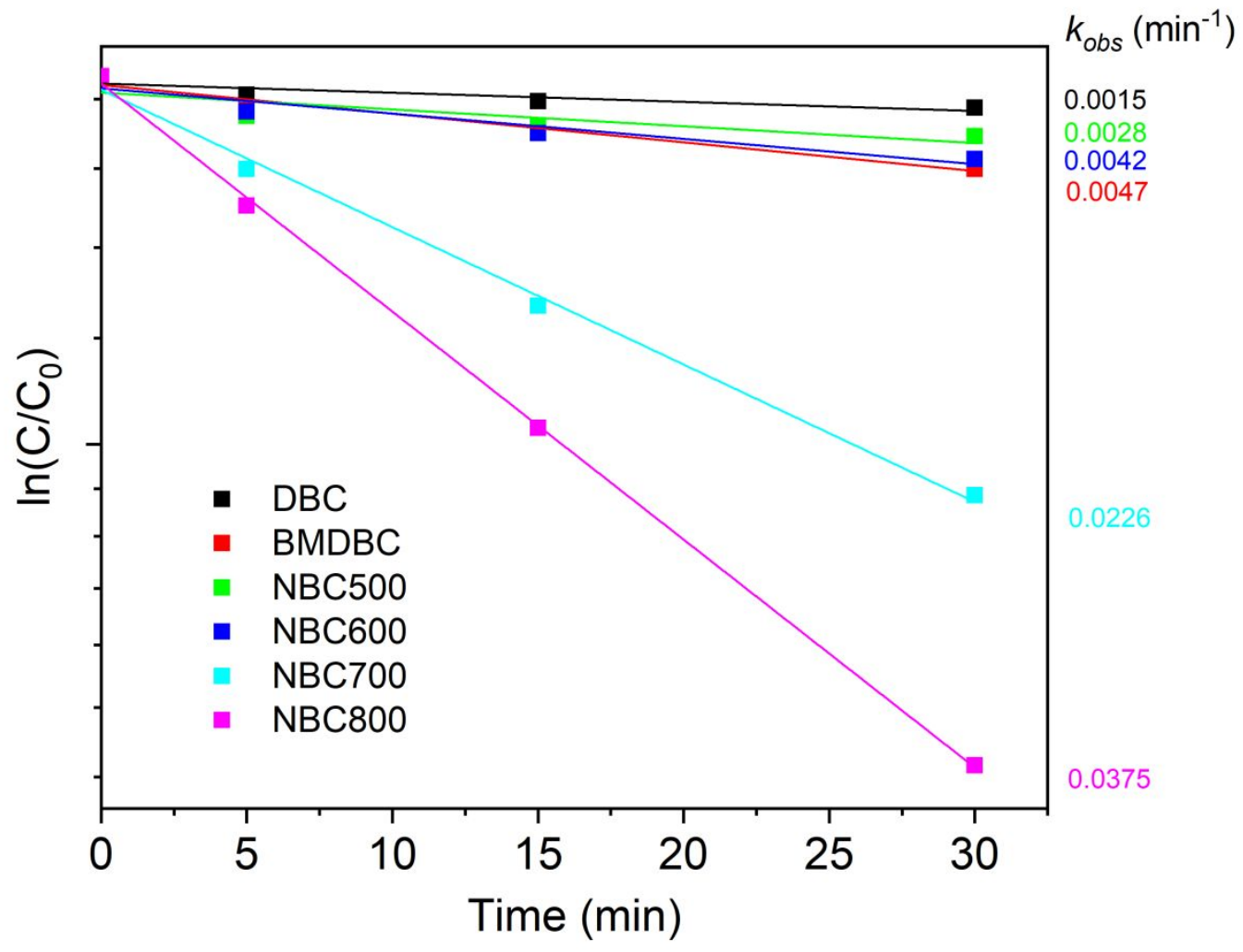

Figure S13. Pseudo first-order fitting for the biochars ([catalysts $]_{0}=500 \mathrm{mg} \mathrm{L}^{-1},[\mathrm{PMS}]_{0}=3.25$ $\mathrm{mM},[4-\mathrm{CH}]_{0}=100 \mathrm{mg} \mathrm{L}^{-1}, \mathrm{pH}_{0}=6.0 \pm 0.2, \mathrm{~T}=25 \pm 1^{\circ} \mathrm{C}$, and reaction time $\left.=30 \mathrm{~min}\right)$. 


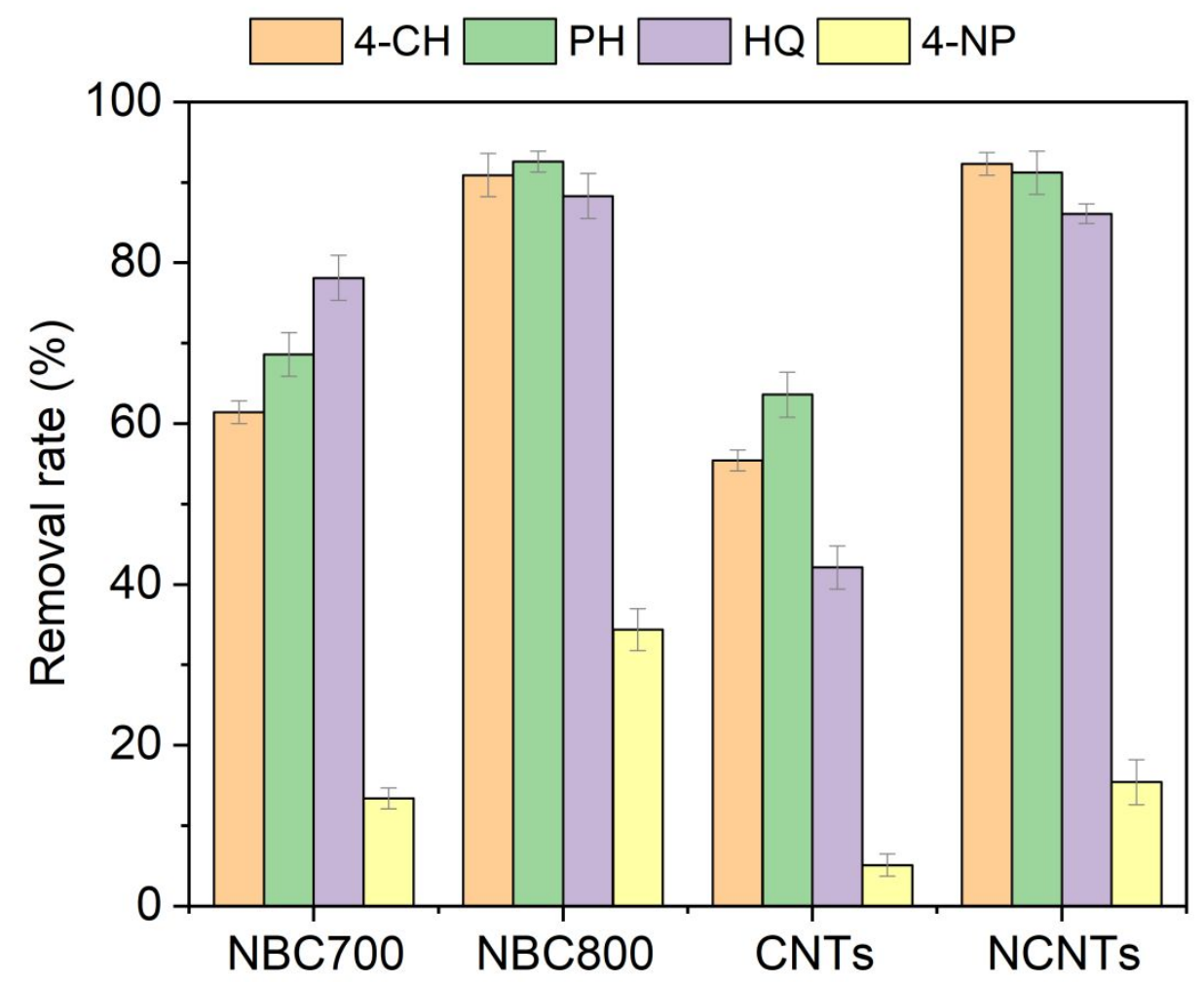

Figure S14. Substrate specificity for the NBCs and CNTs ([catalysts $]_{0}=500 \mathrm{mg} \mathrm{L}^{-1}$, $[\mathrm{PMS}]_{0}=$ $3.25 \mathrm{mM}$, [organics $]_{0}=100 \mathrm{mg} \mathrm{L}^{-1}, \mathrm{pH}_{0}=6.0 \pm 0.2, \mathrm{~T}=25 \pm 1^{\circ} \mathrm{C}$, and reaction time $=180 \mathrm{~min}$ ). 


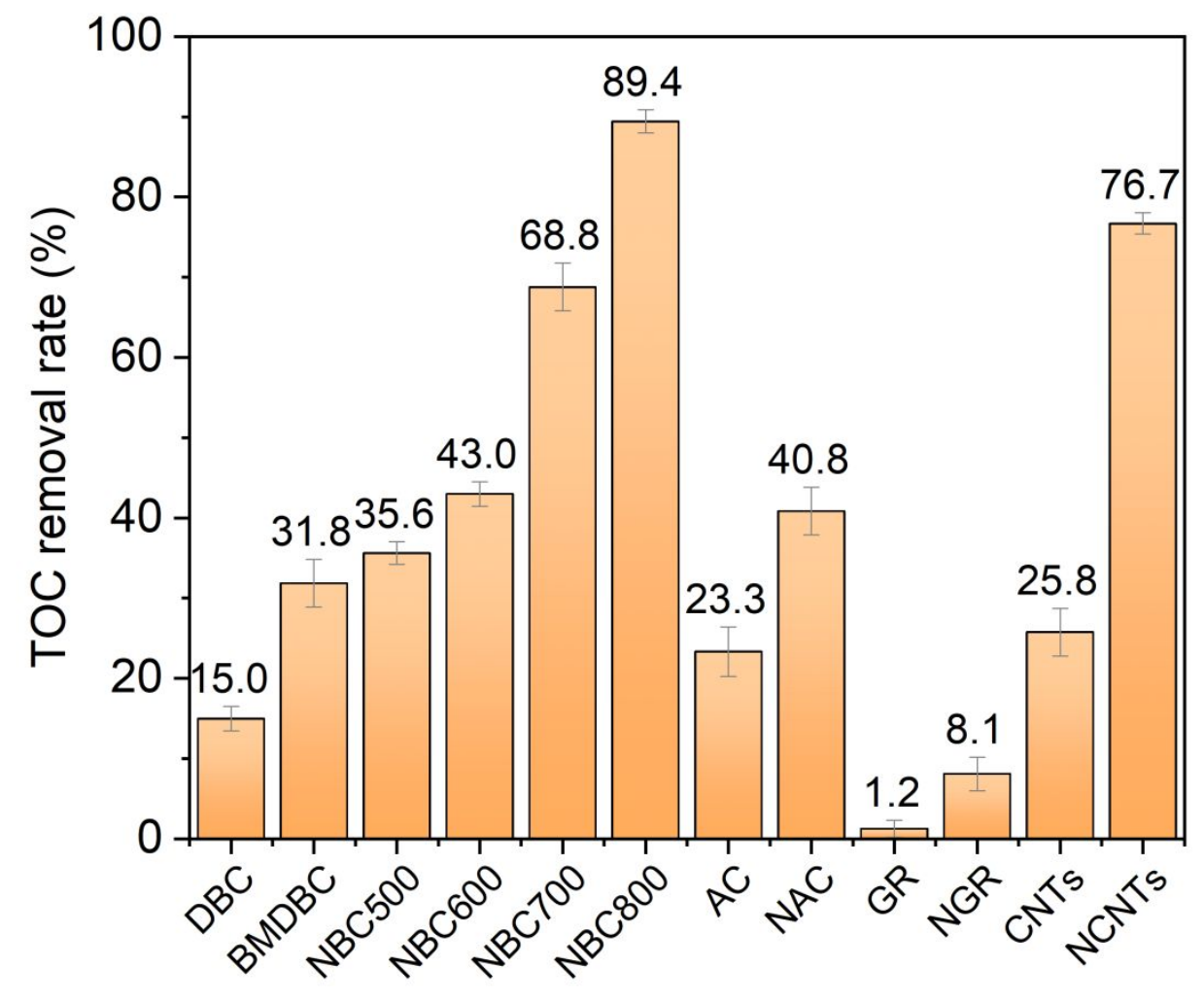

Figure S15. TOC removal by various carbocatalysts in the degradation of the 4-CH ([catalysts $]_{0}$ $=500 \mathrm{mg} \mathrm{L}^{-1},[\mathrm{PMS}]_{0}=3.25 \mathrm{mM},[4-\mathrm{CH}]_{0}=100 \mathrm{mg} \mathrm{L}^{-1}, \mathrm{pH}_{0}=6.0 \pm 0.2, \mathrm{~T}=25 \pm 1^{\circ} \mathrm{C}$, and reaction time $=180 \mathrm{~min})$ 


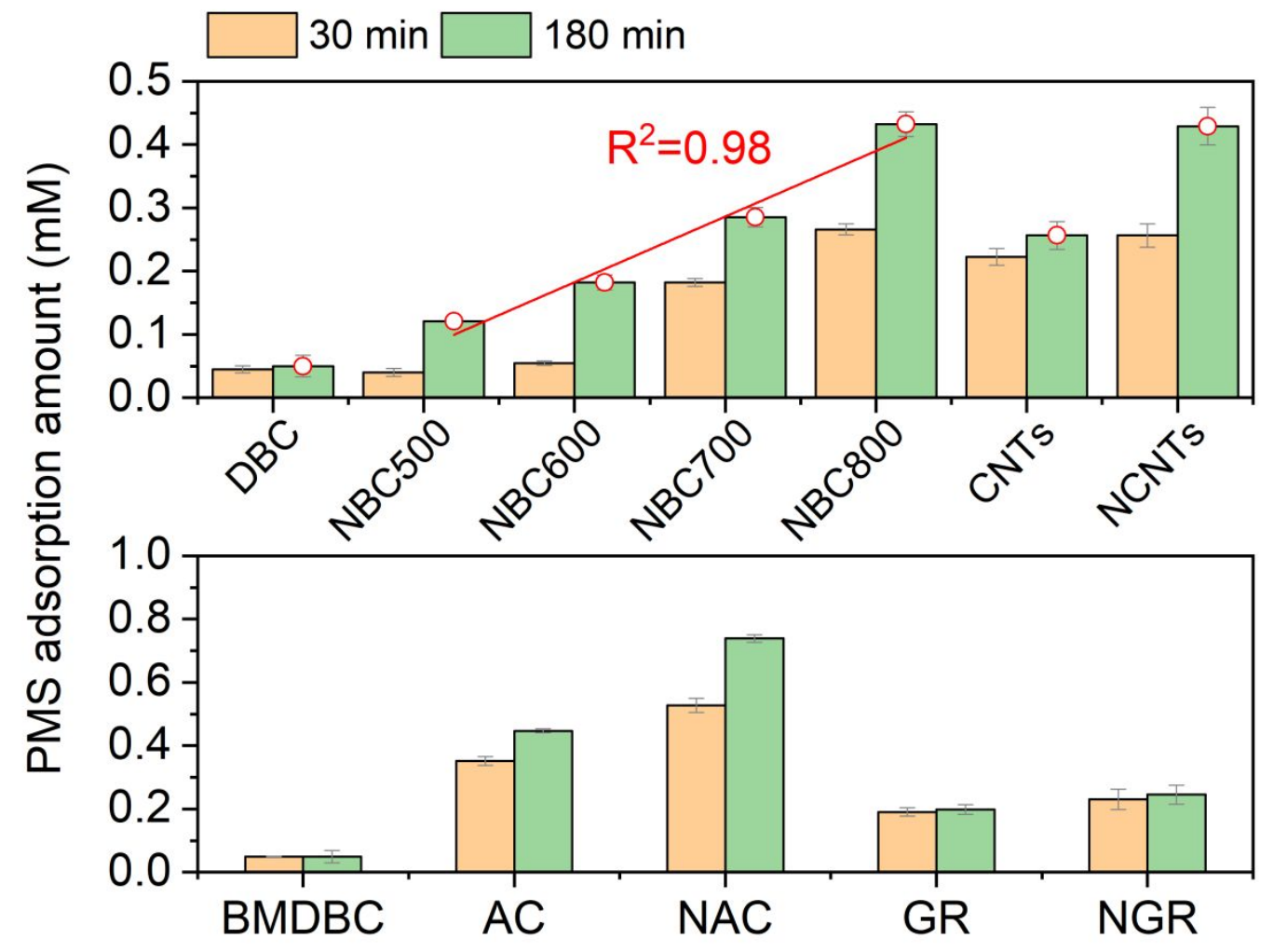

Figure S16. PMS adsorption amounts of various carbons ([catalysts $]_{0}=500 \mathrm{mg} \mathrm{L}^{-1}$, $[\mathrm{PMS}]_{0}=$ $3.25 \mathrm{mM}, \mathrm{pH}_{0}=6.0 \pm 0.2, \mathrm{~T}=25 \pm 1{ }^{\circ} \mathrm{C}$, and reaction time $=30$ or $\left.180 \mathrm{~min}\right)$. 


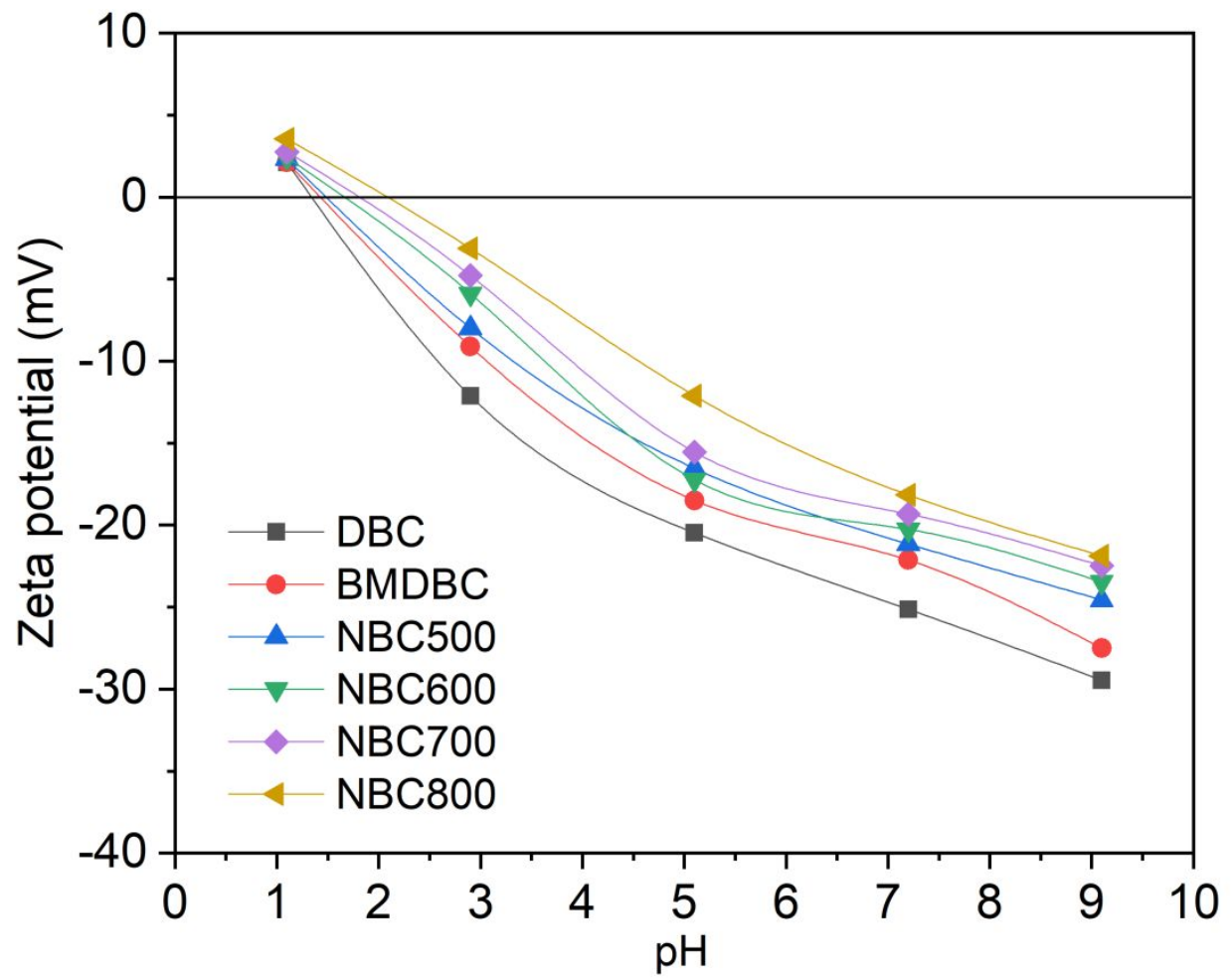

Figure S17. $\mathrm{pH}_{\mathrm{pzc}}$ values of the NBCs. 

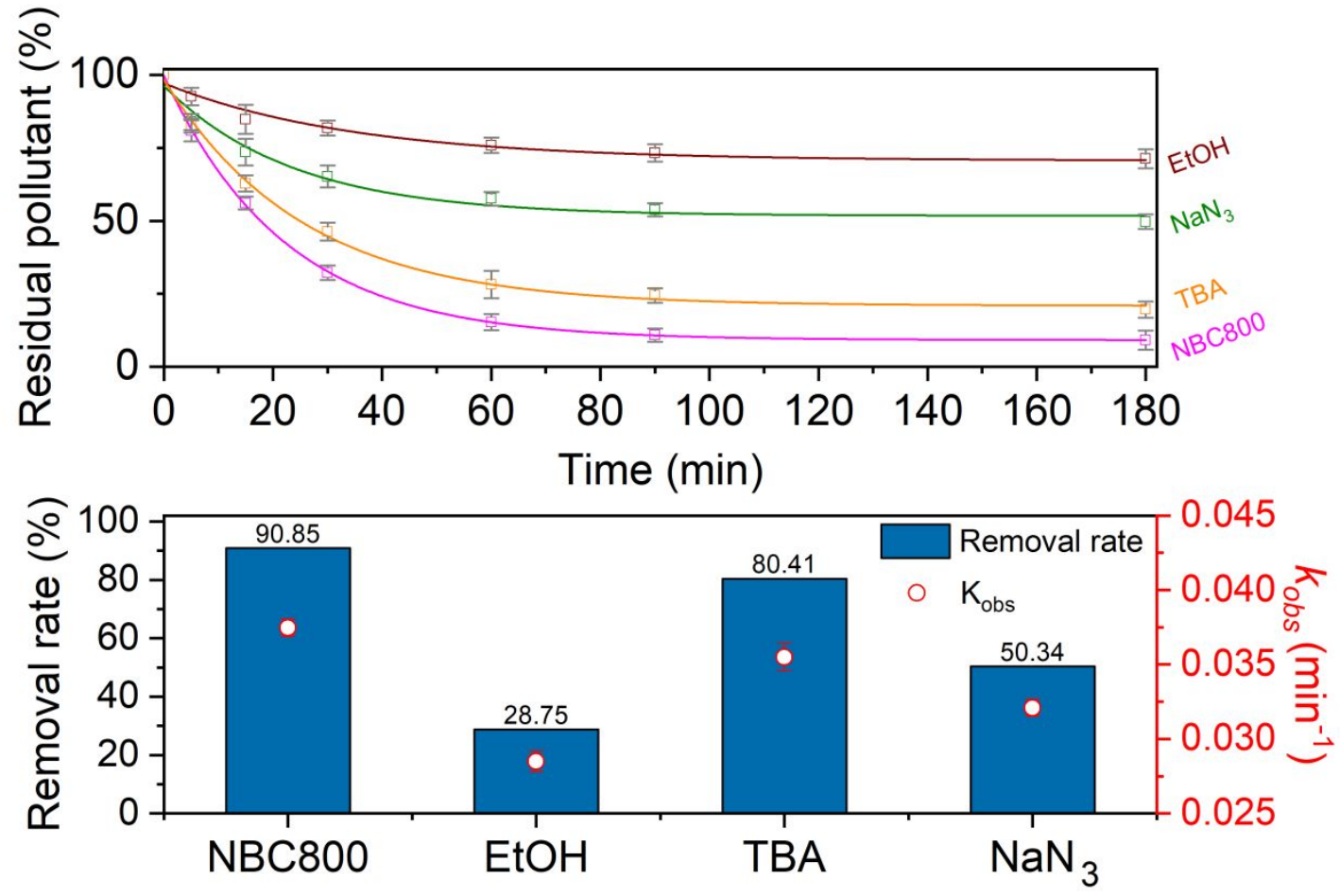

Figure S18. Scavenger experiments for the NBC800 ([catalysts $]_{0}=500 \mathrm{mg} \mathrm{L}^{-1},[\mathrm{PMS}]_{0}=3.25$ $\mathrm{mM},[4-\mathrm{CH}]_{0}=100 \mathrm{mg} \mathrm{L}^{-1},[\mathrm{EtOH} / \mathrm{PMS}]_{0}=500: 1,[\mathrm{TBA} / \mathrm{PMS}]_{0}=500: 1,\left[\mathrm{NaN}_{3} / \mathrm{PMS}\right]_{0}=20: 1$, $\mathrm{pH}_{0}=6.0 \pm 0.2$, and $\left.\mathrm{T}=25 \pm 1^{\circ} \mathrm{C}\right)$. 


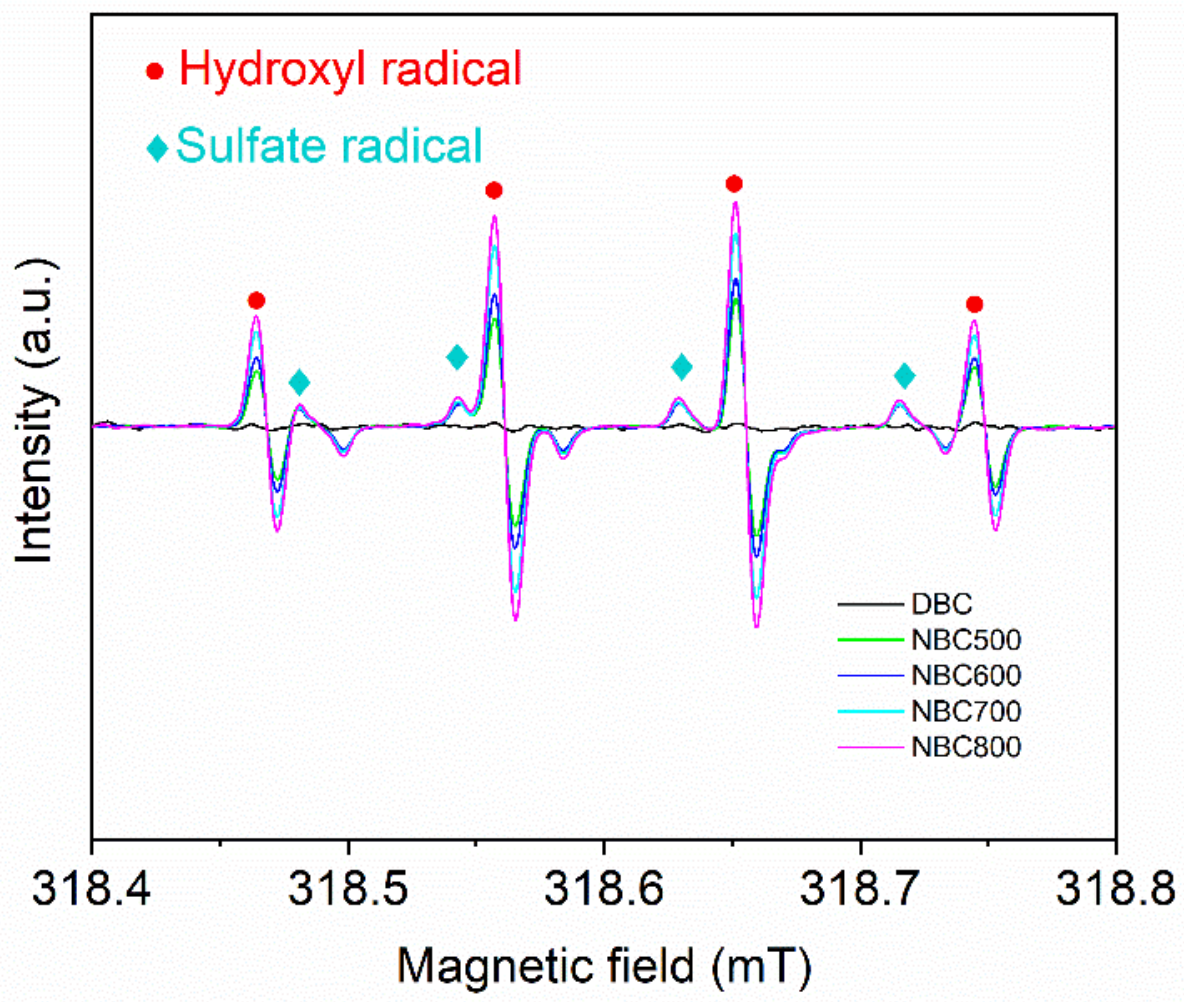

Figure S19. EPR spectrum using DMPO as the spin trapping agent. 


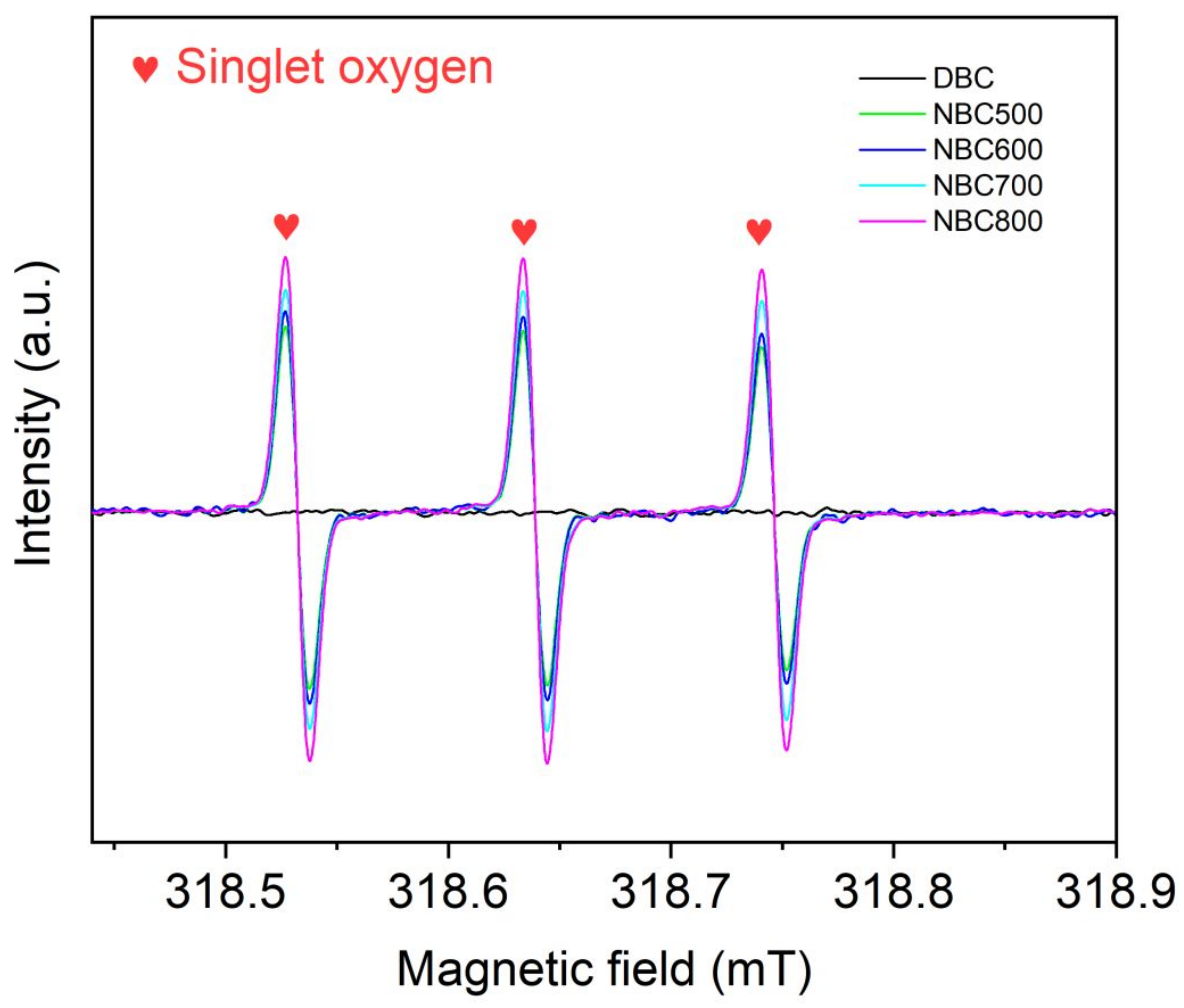

Figure S20. EPR spectrum using TEMP as the spin trapping agent. 


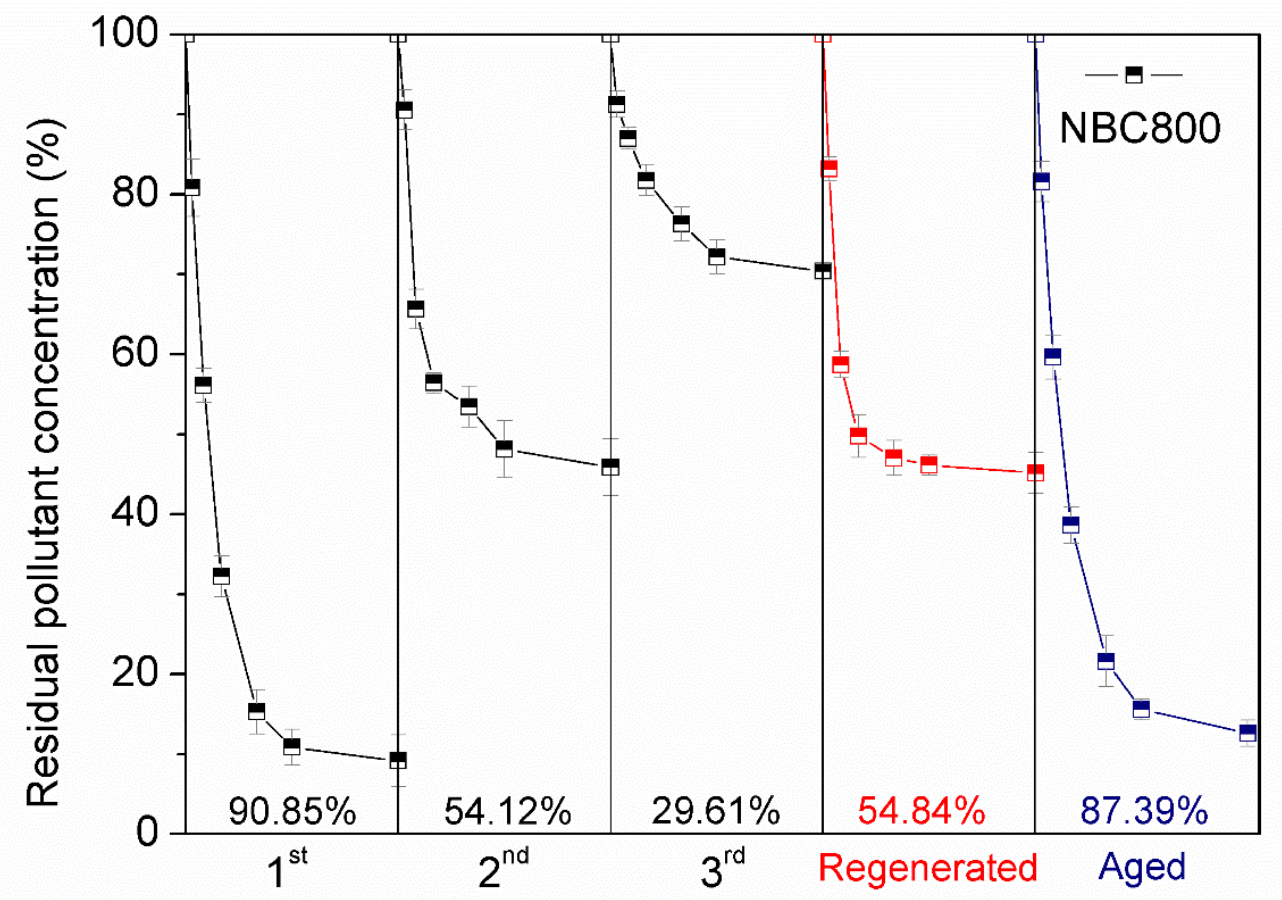

Figure S21. Durability, recyclability, and regeneration tests ([catalysts $]_{0}=500 \mathrm{mg} \mathrm{L}^{-1},[\mathrm{PMS}]_{0}=$ $3.25 \mathrm{mM},[4-\mathrm{CH}]_{0}=100 \mathrm{mg} \mathrm{L}^{-1}, \mathrm{pH}_{0}=6.0 \pm 0.2$, and $\left.\mathrm{T}=25 \pm 1{ }^{\circ} \mathrm{C}\right)$. 


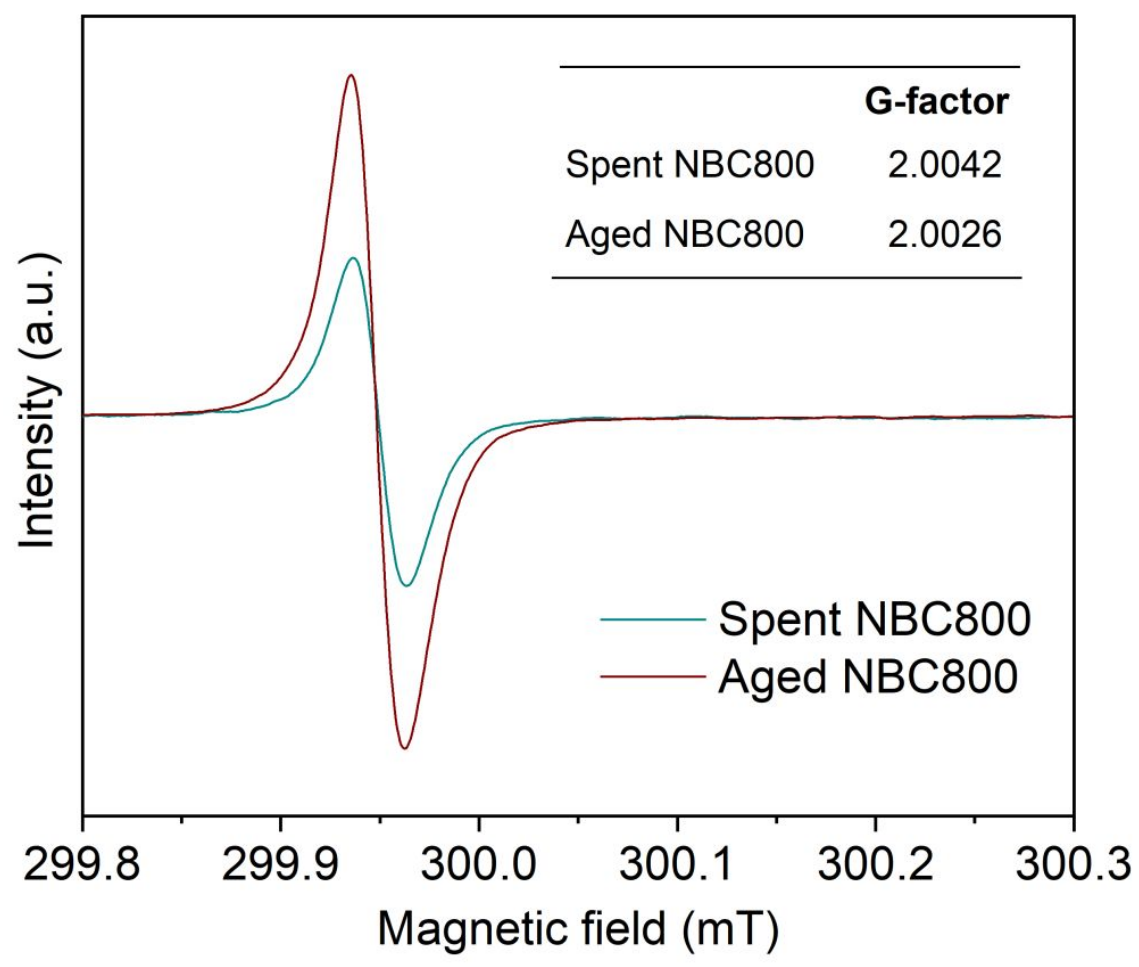

Figure S22. EPR spectra for the spent and aged NBC800. 


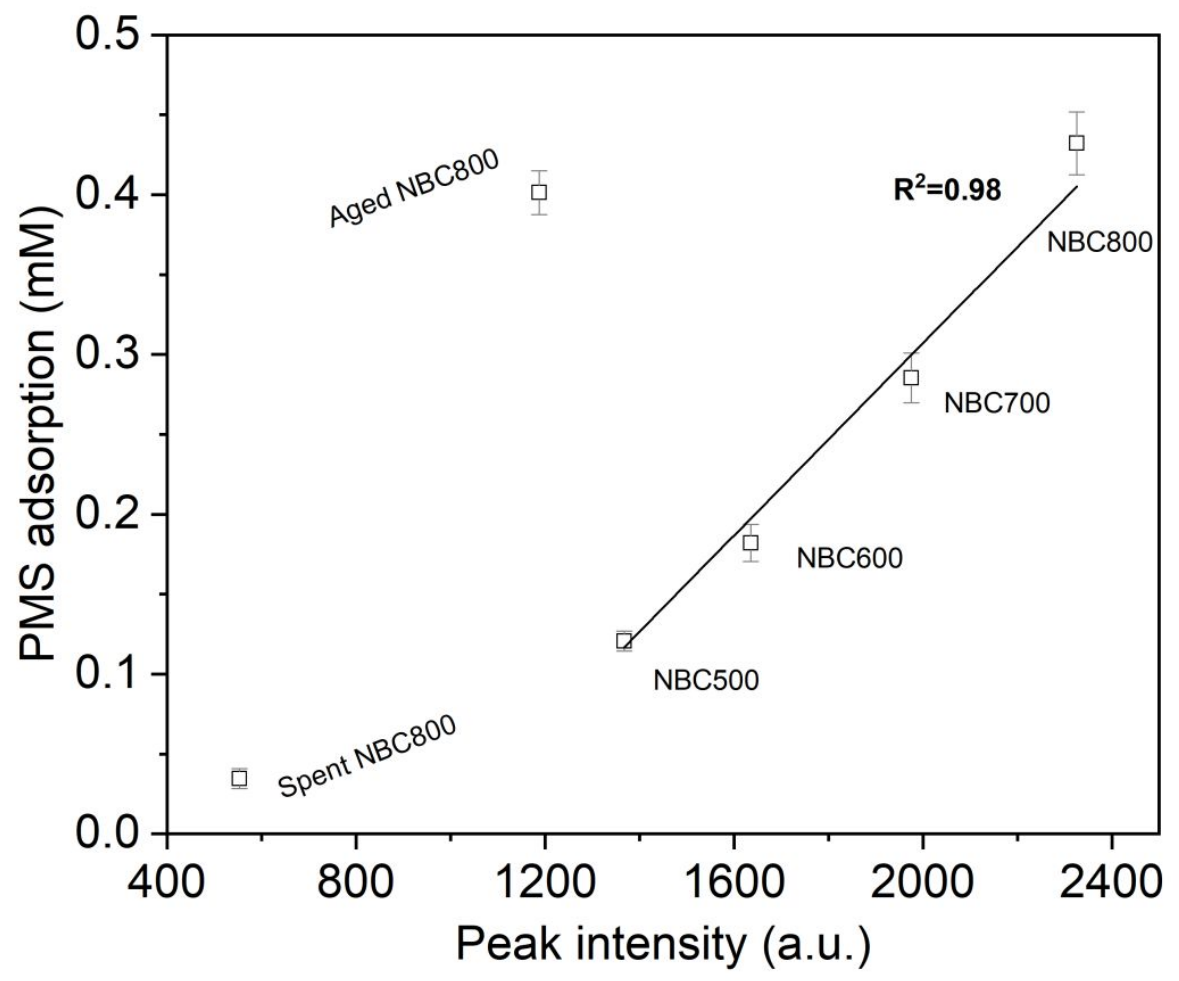

Figure S23. The correlation between peak intensity and PMS adsorptive capacity. 


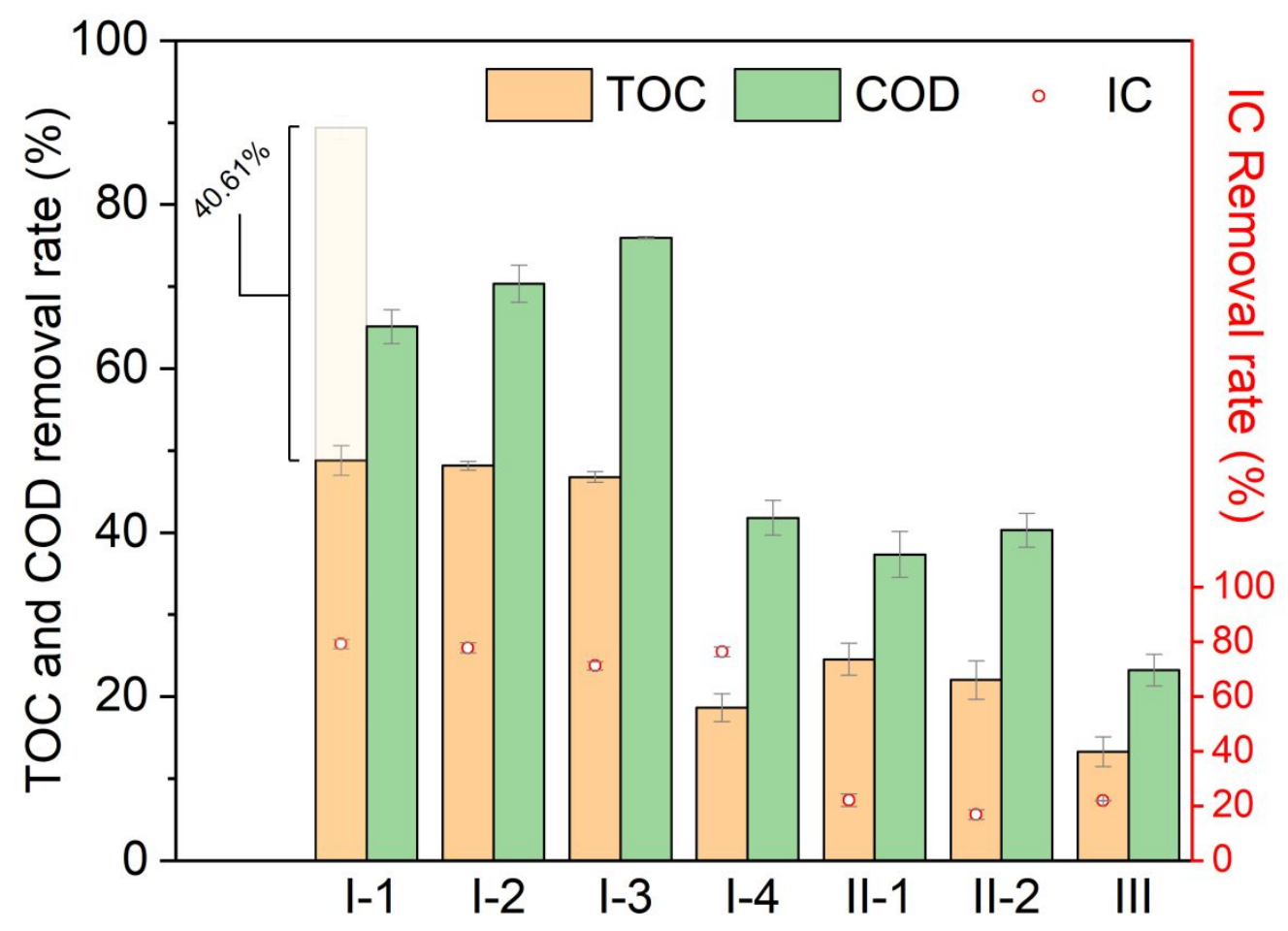

Figure S24. TOC, COD, and IC removal rates under simulated practical conditions. 


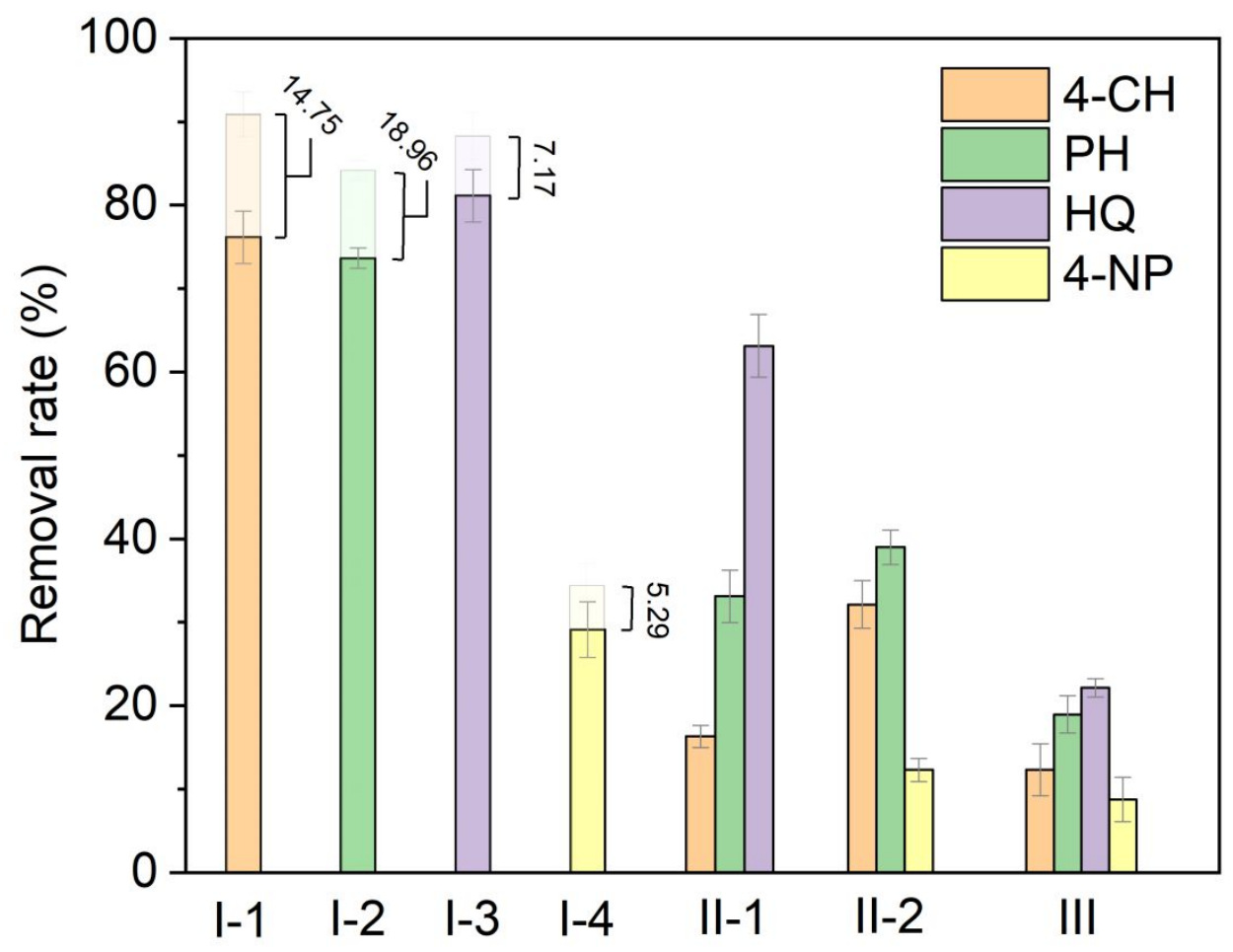

Figure S25. Individual removal of each phenol for different types of simulate wastewater. 


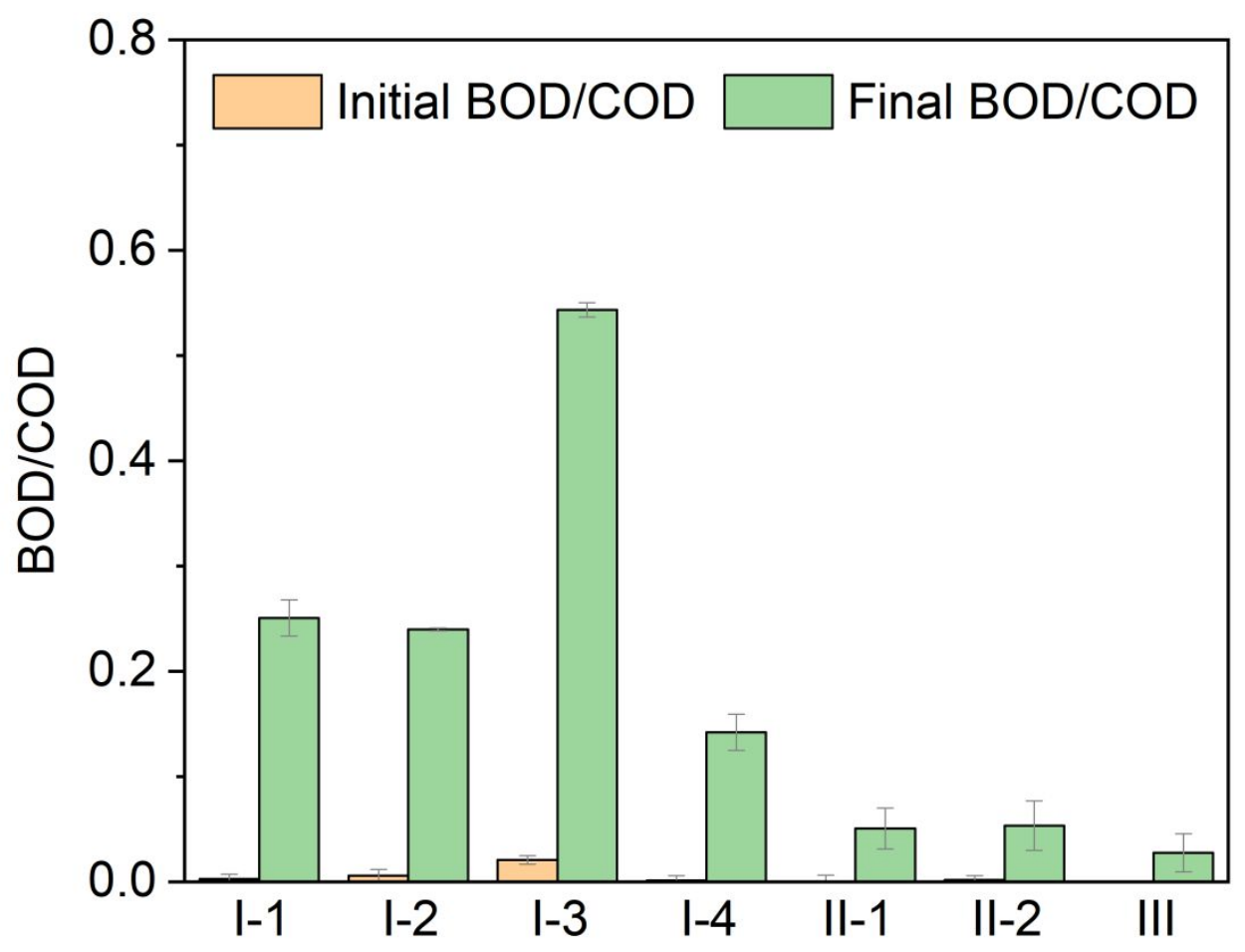

Figure S26. Change of biodegradability after catalytic degradation. 